\title{
Una contribución al estudio de los desastres naturales en Chile Centro Sur: efectos ambientales de las precipitaciones del 26 de junio del 2005 en el área Metropolitana de Concepción.
}

\author{
María Mardones F. \\ Departamento de Ciencias de la Tierra, Fac. de Ciencias Químicas. \\ Universidad de Concepción, mmardone@udec.cl \\ Freddy Echeverría C. \\ Departamento de Geofísica - Fac. de Ciencias Físicas y Matemáticas. \\ Universidad de Concepción, fechever@udec.cl \\ Constanza Jara B. \\ Departamento de Ciencias de la Tierra - Fac. de Ciencias Químicas, \\ Universidad de Concepción, constanzajara@udec.cl
}

\begin{abstract}
RESUMEN
Se analiza el evento pluviométrico excepcional del 26-06-05 que afectó al área metropolitana de Concepción, los procesos de anegamiento, inundación y remoción en masa detonados y el impacto en la población, con el fin de identificar las áreas de mayor riesgo y contribuir a la preparación de planes de gestión de desastres naturales. Para la caracterización de la perturbación pluviométrica se utilizan datos de intensidad de lluvia en 24hrs, 60, 30 y 10 minutos del periodo 1971-1999. Se realizó un catastro de los procesos naturales con impacto negativo en la población, los que fueron localizados y evaluados en terreno y comparados con la carta de peligrosidad realizada por Mardones et al. (1994). Los impactos en la población, los costos de la emergencia y la evaluación de la gestión del desastre se estimaron mediante entrevistas, encuestas y estadísticas compiladas en OREMI, municipalidades de las comunas investigadas, encargados de Protección Civil y vecinos. El desastre fue ocasionado por un solo evento pluviométrico continuo con intensidad de $158 \mathrm{~mm}$ en $20 \mathrm{hrs}$, en Concepción; dejó un total de 5224 damnificados, 36 casas destruidas y 5 personas muertas. Se constata que umbrales de precipitación superiores a $150 \mathrm{~mm}$ en $24 \mathrm{hrs}$, son capaces de detonar catástrofes con efectos graves; que éstos tienen periodos de recurrencia $\geq 20$ años y se validan las áreas de peligrosidad definidas por Mardones et al.(1994). Se consigna un incremento en las áreas con riesgo de anegamiento e inundación relacionadas con el crecimiento de la ciudad. Se analiza la gestión global del desastre y se hacen propuestas para su optimización.
\end{abstract}

Palabras clave: desastre natural, remoción en masa, inundación, gestión del riesgo

\section{A Contribution to the Natural Disasters Study in center-South Chile: Environmental effects of the June 25 of 2005 rainfalls at the Metropolitan Area of Concepción city.}

\footnotetext{
ABSTRACT

The June 25 of 2005 exceptional rainfall event that affect the Concepción metropolitan area is analyzed, considering the flooding and mass remotions processes triggered and their impact on citizens. The subjects were identify the main risk areas and contribute to prepare natural disasters management plans. For the characterization of this rainfall event intensity data for 24 hours, and for 60,30 and 10 minutes were calculated from the 1971-1999 pluvial registers. Also a review of the natural processes with negative impact on citizens was realized including localization, terrain evaluation and comparison with the Mardones et al (1994) hazards chart. The impacts on citizens, the emergency attendance costs and the evaluation of the disaster management were estimated by interviews, inquiries and statistics compiled
} 
by the OREMI (Regional Emergency Bureau), the county authorities, the civil protection responsible and the neighborhood. The disaster situation was triggered by a unique and continuous rainfall event that registers $158 \mathrm{~mm} / 24$ hours intensity at Concepción city, leaving 5224 injured persons, 36 damaged houses and 5 persons dead. Was observed that rainfall over $150 \mathrm{~mm}$ in 24 hours has the sufficient capacity to unchain catastrophes and produce destructive effects. For these events, the statistical analysis shows $\geq 20$ years how recurrence period. The Mardones et al (1994) hazardous areas were validated. An increasing of the flood risks areas with the city sprawl is clear. The general management of the disaster is analyzed and some proposals for optimize it are presented.

Key words: natural disasters, mass remotions, flooding, risk management.

\section{INTRODUCCION}

Un desastre natural es una situación repentina que afecta a una comunidad, producida por la activación de un proceso natural potencialmente peligroso, en la que la vida y los bienes de las personas pueden sucumbir (Instituto Geológico y Minero de España, 1987). Los desastres constituyen una seria disrupción en el funcionamiento de la sociedad, ya que provocan pérdidas humanas, materiales, económicas y ambientales, las que superan la capacidad de respuesta del grupo afectado.

Los sistemas geomorfológicos tienen un carácter autorregulador; cualquier aporte ingente de energía puede cambiar el modo de funcionamiento de un sistema estable a un sistema metaestable (Anguita y Moreno, 1993). Un desastre natural de tipo geologico se genera cuando los factores que regulan el estado morfogenético de un lugar franquean en cascada los umbrales de estabilidad. El umbral correspondería a una situación límite en torno a la cual los factores o variables que controlan el proceso geológico, se modifican, superan valores críticos de ritmo, de intensidad, de sentido o de naturaleza (Coque, 1977). El desastre ocurre cuando la amenaza o peligro natural se transforma en un proceso que desestabiliza el sistema geográfico y cuyos efectos se agravan generalmente por falta de prevención y de capacidad de gestión.

La frecuencia de desastres naturales registrados en el mundo se ha incrementado nota- blemente entre alrededor de 100 eventos por década en 1940, a cerca de 2800 por década en 1990. El 75\% de éstos tiene relación con eventos meteorológicos y procesos asociados, entre los que destacan los procesos de remoción en masa $e$ inundaciones fluviales (Fig. 1). Se estima que en el año 2004 las pérdidas económicas por desastres naturales en el planeta, alcanzaron a 140 billones de dólares; el segundo más alto total anual registrado en los últimos 10 años (el primero fue de 179 billones de dólares, el año 1995).

Junto a las pérdidas económicas también hay pérdida de vidas humanas. Más de 76000 personas muertas, 44000 millones de euros de pérdidas y 254 millones de personas damnificadas, es el balance que dejaron los desastres naturales durante el 2003, según datos aportados por la Agencia Española de Cooperación Internacional (AECI)). En la segunda mitad del siglo $\mathrm{XX}$, los desastres naturales provocaron la muerte de más de 2,8 millones de personas en el planeta, con una tasa de incremento anual de un $6 \%$ desde 1960 , el doble de la tasa de crecimiento demográfico mundial (OFDA/CRED, 2003). Como consecuencia del crecimiento demográfico sostenido, de la concentración de la población, de la pobreza en las grandes ciudades y de las condiciones caóticas del proceso de urbanización, particularmente en los países del Tercer Mundo, se estima un incremento cada vez mayor de la ocurrencia de desastres. La expansión urbana es condicionada por factores económicos, socioculturales y políticos independientemente de la capacidad de acogida del territorio; esto conlleva el crecimiento de la urbe 
en áreas de riesgo y en condiciones precarias de construcción, lo que aumenta la vulnerabilidad a la disrupción frente a las amenazas naturales (OFDA/CRED, 2003). A todo lo cual se agrega, la carencia de programas integrales y permanentes de gestión del desastre, que incluyan métodos de mitigación y prevención.

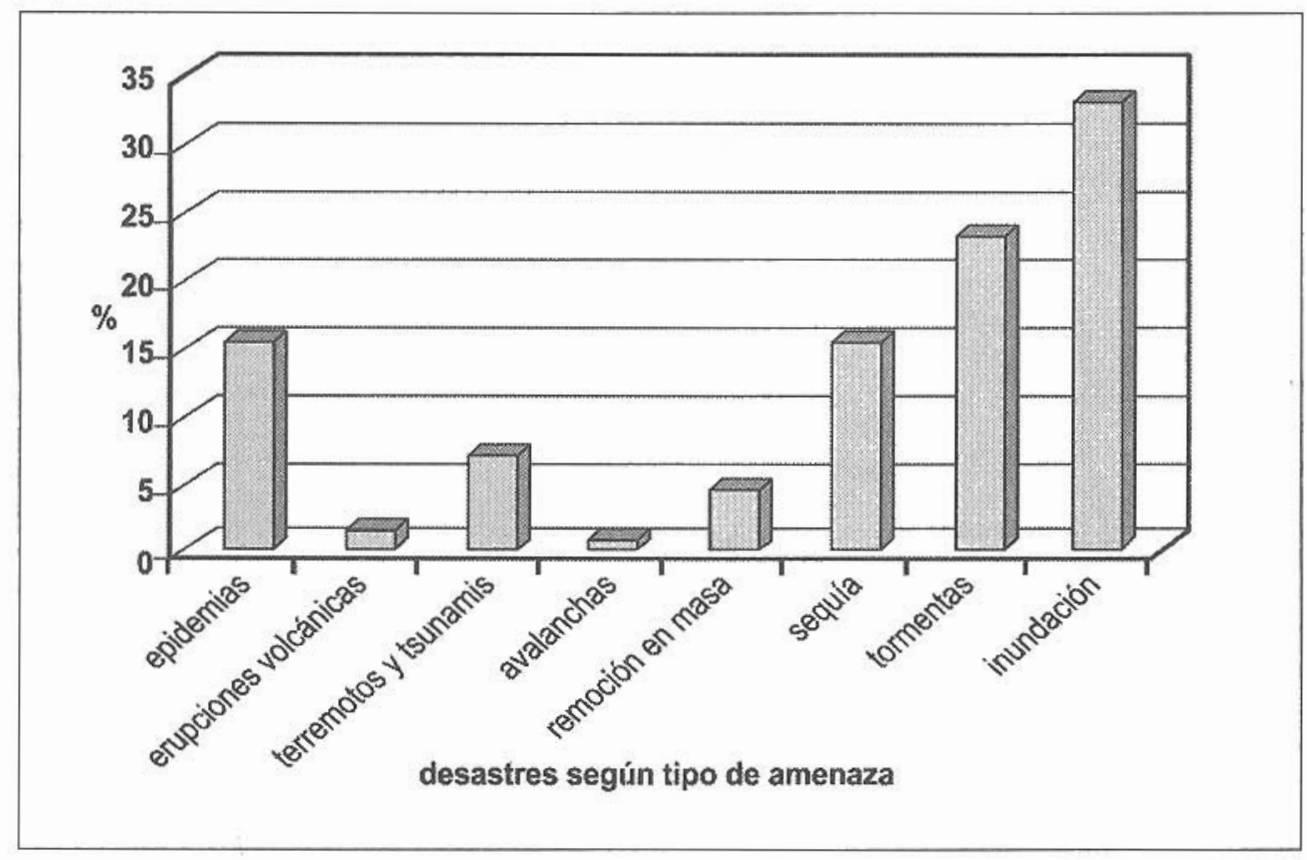

Fuente: EM-DAT: The OFDA/CRED International Disaster Database

Fig.1. Desastres naturales en el Mundo, según tipo de amenaza. 1994-2003

La ciudad de Concepción y su área metropolitana, se localiza en el margen costero de la Región del Biobío (Chile), centrada en las coordenadas $36^{\circ} 50^{\prime} \mathrm{S}$ y $73^{\circ} 02^{\prime} \mathrm{W}$ (Fig.2). En razón de sus características físicas y demográficas, es una de las urbes del país frecuentemente afectada por desastres naturales asociados a eventos climáticos. La ciudad se emplaza en un marco geomorfológico de bloques y fosa, estructurado por la tectónica de falla y modelado por la acción del mar y de los ríos Biobío y Andalién. Al E, la Cordillera de la Costa conformada de rocas graníticas de edad paleozoica con mantos de alterita de potencias de hasta $27 \mathrm{~m}$ (Galli, 1967), se eleva más de $100 \mathrm{~m}$ sobre la llanura, a través de un escarpe de falla de dirección NNE-SSW. El borde costero, está enmarcado por dos penínsulas rocosas: Tumbes y Hualpén, estructuradas por rocas metamórficas y graníticas de edad paleozoica, profundamen- te meteorizadas y solevantadas por la tectónica a más de 100 m.s.n.m. Entre ambos relieves se emplaza la fosa tectónica de Concepción-Talcahuano, al interior de la cual se modela la llanura fluvial y deltaica del río Biobío, con altitudes que escasamente sobrepasan los 10m y conformada por depósitos de arenas negras basálticas procedentes del alto valle del Laja (Mardones, 2002). Durante el Holoceno, el río difluyó en el delta modelando paleocanales orientados hacia las bahías de San Vicente, Concepción y hacia el río Andalién. Como éstos presentan fuertes dificultades para el drenaje de aguas/lluvia, han sido progresivamente rellenados y colonizados por la urbe durante el siglo XX. De la llanura emerge una cadena de cerrosisla con altitudes medias de $70 \mathrm{~m}$, constituidos por roca sedimentaria de edad Cenozoico inferior y medio, de estructura monoclinal y fallada, cubiertos por suelos con potencias $\geq 7 \mathrm{~m}$. 


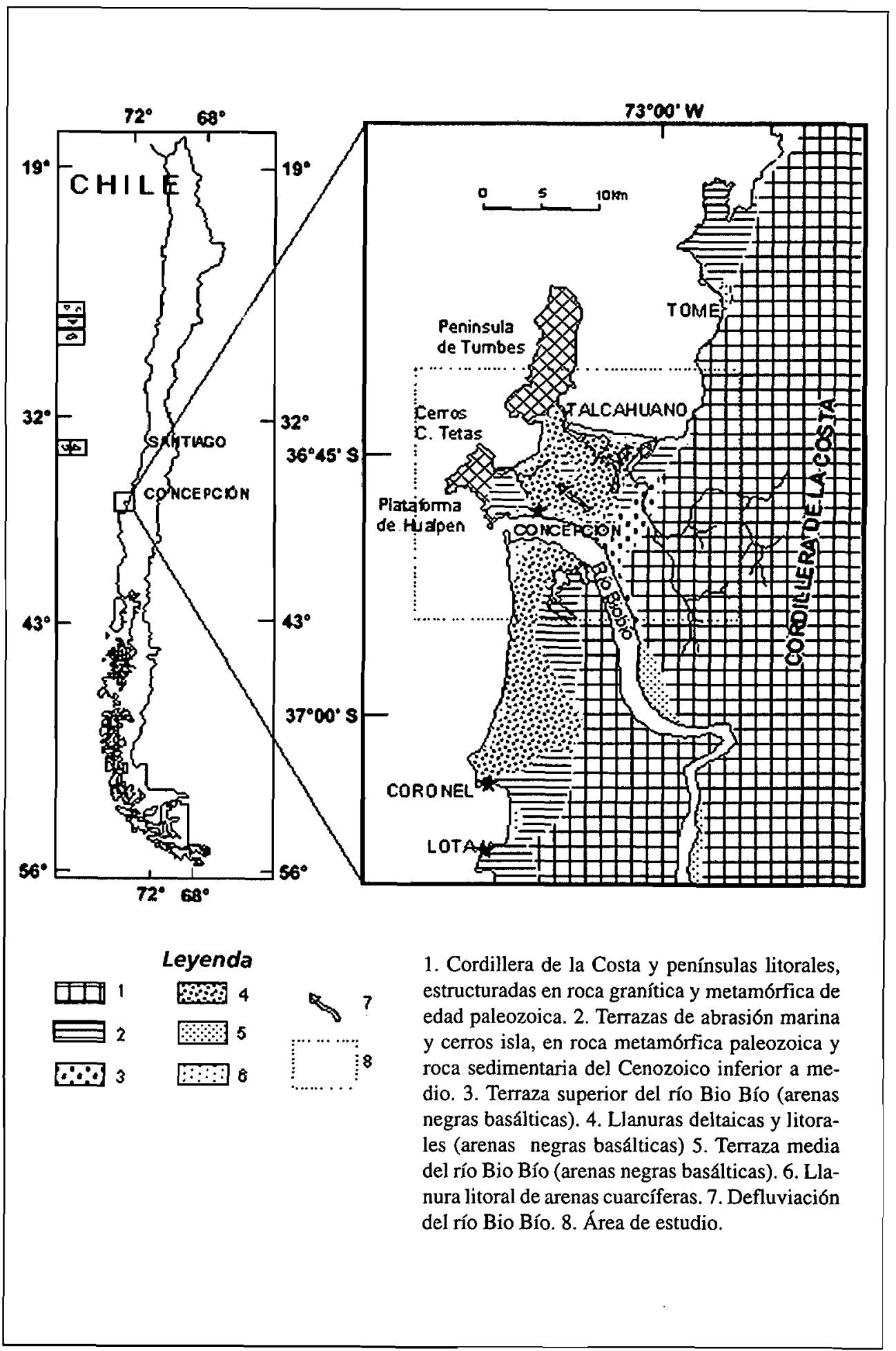

Fig. 2. Localización del Área de Estudio 
Son estos relieves montañosos con pendientes topográficas $>20^{\circ}$ y rocas muy alteradas en las laderas de los cerros, factores que contribuyen a la ocurrencia de procesos de remoción en masa; mientras que los paleocanales y humedales de la llanura deltaica, favorecen el desarrollo de inundaciones y anegamientos.

Desde el punto de vista climático, se reconoce en el área un clima templado mediterráneo, con una estación invernal lluviosa, una estación estival seca y cálida y una fuerte variación interanual de la intensidad pluvial (Romero, 1985). Estas características pluviométricas serían el principal detonante de inundaciones, anegamientos y procesos de remoción en masa.

El área metropolitana de Concepción es considerada por su peso demográfico el segundo conglomerado urbano de Chile. El censo del 2002 acusa un total de población de 1.436.104 habitantes para la Región del Biobío, de los cuales el $77.1 \%$ vive en ciudades y el $43,24 \%$ lo hace en la conurbación Concepción-Talcahuano. La densidad media del área metropolitana es de $52.2 \mathrm{~h} / \mathrm{km}^{2}$; aunque ésta puede superar los $1500 \mathrm{hab} / \mathrm{km}^{2}$, en los distritos más poblados emplazados en las llanuras inundables o anegables (Andalién: 1513hab $/ \mathrm{km}^{2}$, Hospital: $1683 \mathrm{hab} / \mathrm{km}^{2}$ ) y hasta más de $900 \mathrm{hab} / \mathrm{km}^{2}$ en distritos ubicados en los cerros de la ciudad de Talcahuano (Co David Fuentes: 934 hab/km²) con ame- nazas de procesos de remoción en masa (INE, 2002). Aunque el ritmo de crecimiento ha disminuido en las últimas décadas de $20 \%$ en el periodo 1982-1992, a $6 \%$ entre 19922000 y a $1 \%$ entre el 2000 y 2005 , los buenos sitios de fundación han sido tempranamente saturados y la expansión especialmente de los estratos sociales más pobres, desborda hacia sectores poco aptos para ser habitados (cerros, paleocanales, llanuras aluviales, sectores de humedales, etc.) y expuestos a fuertes índices de peligrosidad natural. A esto se agrega la mala calidad de las viviendas, la insuficiencia de equipamientos e infraestructuras, todo lo cual contribuye a aumentar la vulnerabilidad humana frente a una amenaza natural.

Mardones y Vidal (2001) estimaron que para el periodo 1960-1992, de una superficie total estudiada de $223.87 \mathrm{~km} 2$ en la zona de Concepción-Talcahuano, un 15\% estaba expuesta a riesgo alto a medio de procesos de remoción en masa, un $7.9 \%$ a riesgo de anegamiento ( $\sin$ considerar el área de humedales que representa el $9 \%$ ) y $9.87 \%$ a riesgo de inundación fluvial, de los cuales un $4 \%$ correspondía al curso inferior del río Aṇdalién y Estero Nonguén. Estas condiciones de amenaza explican la frecuencia de desastres naturales en el área, los que sin ser de gran magnitud producen efectos económicos y ambientales importantes para la población penquista. (Fig. 3).

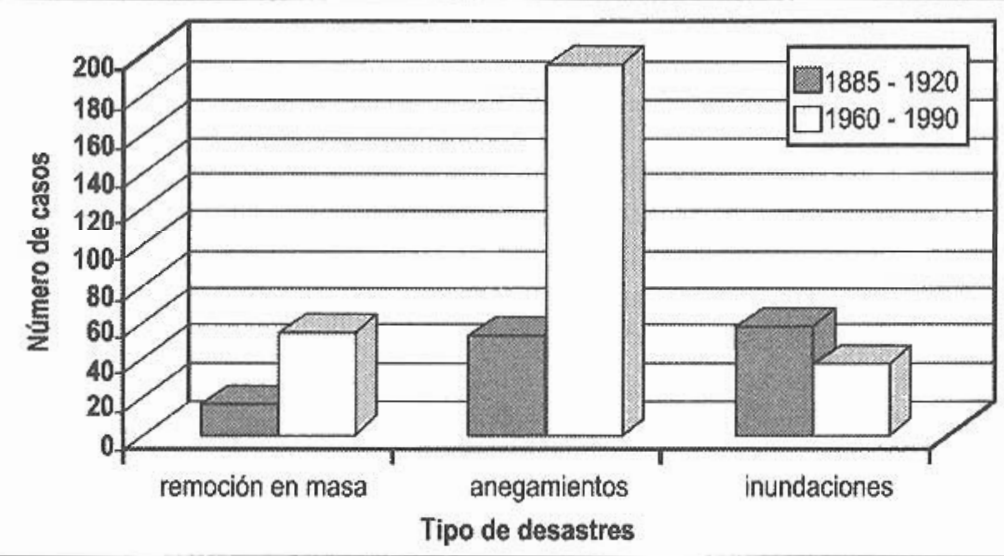

Fuente datos: Diario El Sur 1885 - 1920 y 1960 - 1990

Fig.3 Desastres naturales en las comunas de Concepción y Talcahuano, periodos 1885 1920 y $1960-1990$ 
Alarcón (1995) y Essman (1997) han documentado la frecuencia de desastres en dos periodos: $1885-1920$ y 1960-1990. En la Figura 3 se constata un incremento notable del número de casos de anegamiento y procesos de remoción en masa, registrados en el periodo más reciente. Si se asume que el sistema físico no experimenta cambios importantes, es posible señalar que el incremento de los procesos de remoción en masa se relacionaría con el poblamiento de áreas expuestas a amenazas naturales, especialmente las laderas de los cerros, mientras que los anegamientos se harían más frecuentes producto del incremento de las áreas pavimentadas e impermeabilizadas por la urbanización, sin que se implemente simultáneamente un sistema de drenaje de aguas-lluvia. La disminución de las inundaciones refleja el menor número de eventos asociados al río Biobío, cuya ribera norte ha sido manejada, especialmente en la segunda mitad del siglo $\mathrm{XX}$. De modo que los desbordes fluviales registrados recientemente en el área metropolitana, se relacionarían preferentemente con crecidas de los ríos Andalién y su afluente el Estero Nonguén.

Cada episodio de lluvia excepcional en el sector litoral de Concepción, genera extensos anegamientos, inundaciones fluviales y numerosos procesos de remoción en masa, cuya magnitud es directamente proporcional a la magnitud del meteoro. El impacto es diferencial, espacial y socialmente y expone una serie de problemas asociados a la falta de previsión y de planificación.

Durante el mes de junio del 2005 se produjo una lluvia de origen frontal en el litoral de Concepción que provocó 5 personas fallecidas, 36 casa destruidas y más de 4800 damnificados. El agua precipitada provocó procesos de remoción en masa en las laderas de los cerros y anegó e inundó los sectores topográficamente deprimidos de la ciudad. Se propone que tales efectos estarían relacionados con la intensidad de lluvia diaria y con la modalidad de gestión del desastre.
El objetivo de esta investigación es: analizar el evento pluviométrico del 26-06-05 que afectó al área metropolitana de Concepción y los procesos geomórficos e hidrológicos asociados y evaluar los efectos en la población, con el fin de identificar las áreas de mayor riesgo y contribuir a la preparación de planes de gestión para enfrentar futuros desastres.

\section{METODOLOGIA}

Para estimar el efecto que tuvieron las precipitaciones en la detonacion del desastre ocurrido el 26 de junio del 2005, se analizó la intensidad de lluvia en 10, 30, 60 minutos y $24 \mathrm{hrs}$, con datos aportados por INPESCA (Instituto de Investigación Pesquera de Talcahuano). Estos fueron comparados con eventos similares ocurridos en el área, en base a información pluviométrica registrada en las últimas décadas por las estaciones meteorológicas de Carriel Sur (Talcahuano) y Bellavista (Concepción). No fue posible determinar el histograma de crecida del Estero Nonguén por la falta de una estación fluviométrica de registro continuo; se explica el impacto de las lluvias en el sistema fluvial a través de encuestas realizadas a los pobladores afectados y de datos de caudales mensuales del río Andalién registrados por la Dirección General de Aguas (D.G.A.).

En terreno, se realizó un catastro de los procesos naturales (inundación, anegamiento y procesos de remoción en masa) con impactos negativos en la población, ocurridos entre el 26 y 27 de junio del 2005. Estos fueron localizados, evaluados y vaciados en la carta de peligrosidad elaborada por Mardones et al. (1994). Se realizó in situs el levantamiento morfométrico y composicional de taludes y depósitos. El análisis de arcilla del material remocionado fue realizado en el Laboratorio del Instituto GEA de la Universidad de Concepción.

Los impactos sobre la población y los costos de la emergencia se estimaron a través de 
encuestas en terreno y principalmente con las estadísticas registradas por OREMI y por las Municipalidades de las comunas de Chiguayante, Talcahuano y Concepción. Finalmente la evaluación de la gestión del desastre, se logró mediante entrevistas a encargados de Protección Civil, OREMI (Oficina Regional de Emergencia) y vecinos de las comunas afectadas.

\section{RESULTADOS}

\section{I.-EL REGIMEN PLUVIOMETRICO INVERNAL DE CONCEPCION}

\section{1.-Las Perturbaciones Pluviométricas Frecuentes}

Concepción tiene un clima mediterráneo transicional, con influencias anticiclonales cálidas dominantes en verano y ciclonales templadas en invierno (Romero, 1985). Cuatro meses frío-húmedos agrupan entre el 62 al $75 \%$ de las precipitaciones anuales que varían de $850 \mathrm{~mm}$ en el borde costero (Punta Hualpén) a $1300 \mathrm{~mm}$ en Concepción (Devynck, 1970). La estación de invierno ofrece la más alta frecuencia de mal tiempo (3 a 15 días de lluvia por mes), asociada a las perturbaciones del Frente Polar. Como es normal para la latitud, la componente zonal del viento orienta el desplazamiento de las perturbaciones de $\mathrm{W}$ a $\mathrm{E}$ y de $\mathrm{S}$ a N.

De mayo a agosto se concentra el $70 \%$ de las precipitaciones, el mes con más número de días de lluvia es Junio con 16-17 días de lluvia para Concepción y 14 para Talcahuano. Devynck (1970) estimó que el intervalo más frecuente de lluvia diaria para el periodo $1965-69$ fue de $6-40 \mathrm{~mm}$ diarios. En estos 5 años se registraron 24 casos con 1luvias superiores a $40 \mathrm{~mm}$. Perturbaciones normales de invierno con fuerte circulación zonal en altura y el desarrollo de depresiones asociadas a sistemas frontales que sufren una rápida oclusión al desplazarse sobre el continente y abordar la Cordillera Andina, serían responsabies de la mayor parte de las lluvias intensas que se producen en la Región del Biobío en invierno.

La Fig. 4 muestra la frecuencia de precipitaciones máximas diarias, según intervalos de intensidad para un periodo de 28 años (1965-1999) en Concepción. Se destaca allí que la mayor frecuencia se presenta en los intervalos 60 a $80 \mathrm{~mm}$ ( $40 \%$ de los casos) y un $66 \%$ de los eventos se concentra entre 50 a $90 \mathrm{~mm} / 24 \mathrm{hrs}$. Ninguno de estos eventos individualmente considerados se asocia a de-

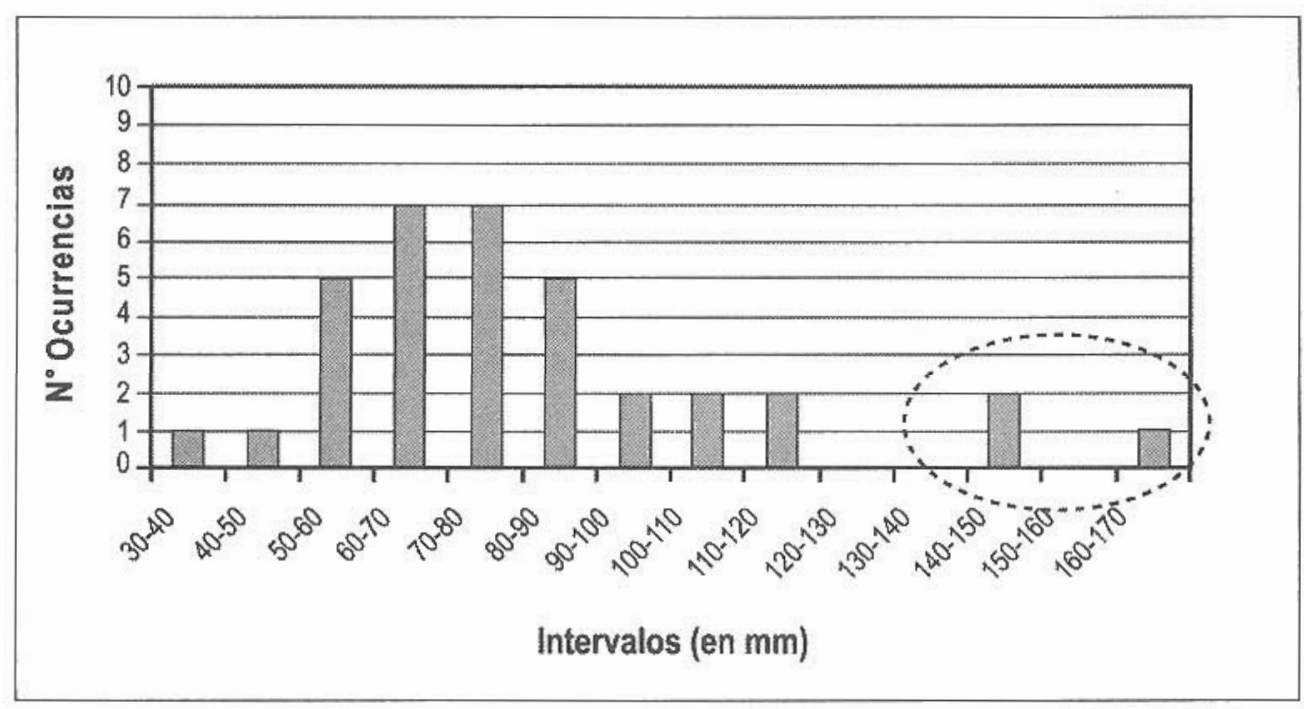

Fig. 4 Frecuencia de Precipitaciones Máximas Diarias, según intervalos de intensidad. Estación Metereológica Bellavita. 1965 - 1999 


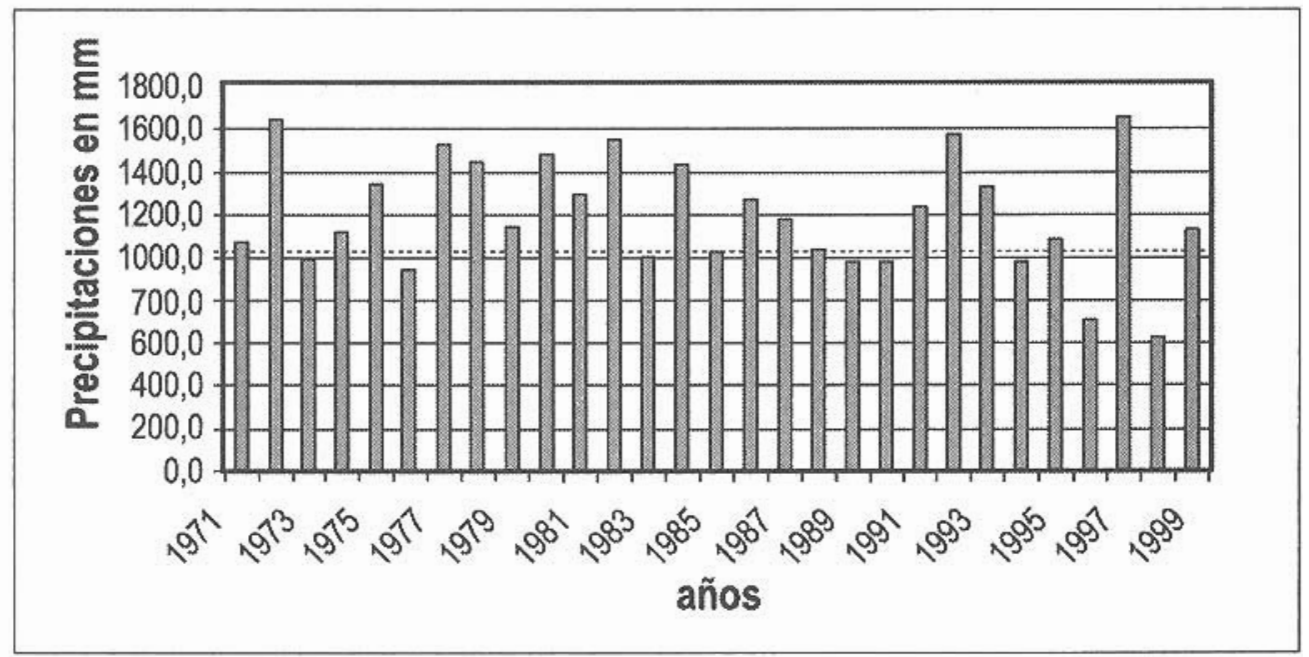

Fig. 5 Precipitaciones Anuales 1971 - 1999, Estación Bellavista-Concepción

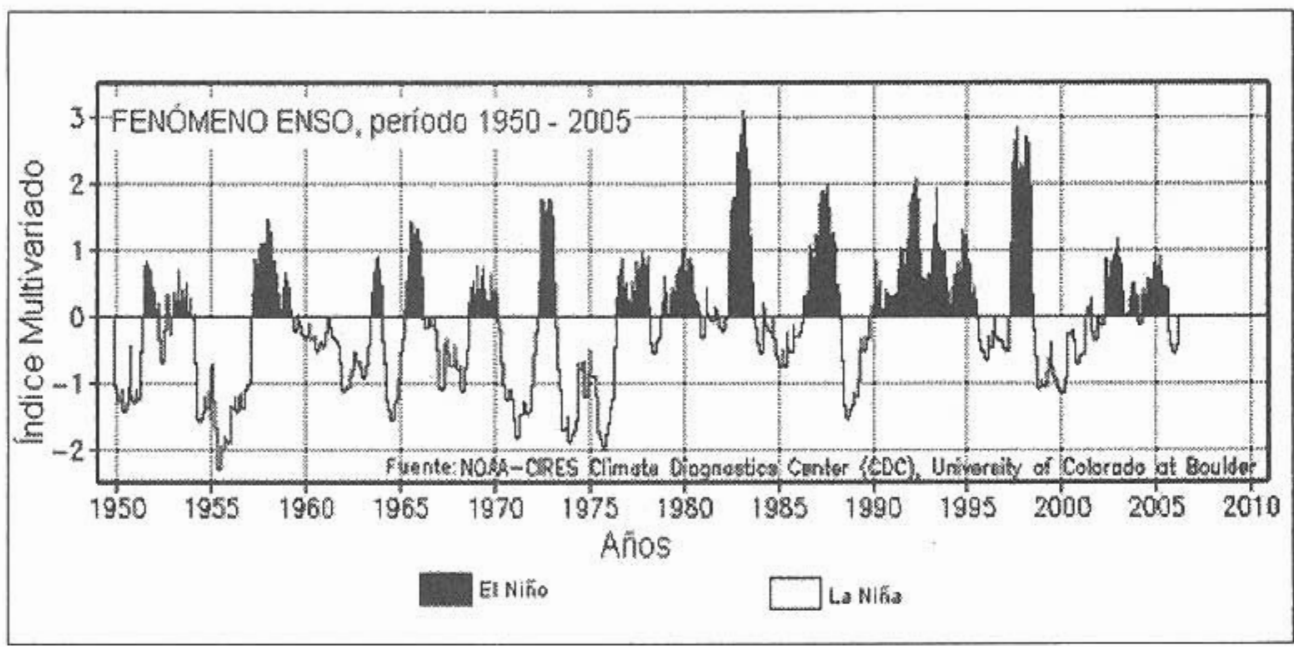

Fig. 6 Fenómeno ENOS, periodo 1950 - 2005

sastres. El círculo marca los rangos extremos de intensidad de lluvia, los que registran 3 casos para el periodo: dos ocurrencias para el intervalo $140-150 \mathrm{~mm}$ y una para el intervalo $160-170 \mathrm{~mm}$.

\section{2.-Las Perturbaciones Pluviométricas Excepcionales}

El análisis de los valores anuales de las precipitaciones hace aparecer la extrema variabilidad interanual de la pluviometría. Para el periodo 1931-1960, Devynck (1970) estima 11 años húmedos, 12 años secos y solo 7 años normales (cercanos al promedio). La Fig. 5 grafica en línea punteada para el periodo 1971-1999, el promedio pluviométrico anual de $1199 \mathrm{~mm}$; se aprecia una variabilidad semejante al periodo 1931-1960: 11 años húmedos, 8 años secos y 10 años normales, registrándose un máximo de $1653 \mathrm{~mm}$ en 1972 y un mínimo de $617 \mathrm{~mm}$ en 1998. Esta variabilidad es característica de la zona mediterránea chilena, donde la mayoría de los periodos de sequía o de mayor pluviosidad son asociados al ciclo ENOS (El Niño-Oscilación del Sur) (Romero, 1985; Pizarro y Montecinos, 2004). Si se comparan las Figs. 5 y 6 se constata que de 11 años húmedos, 5 son hiperhúmedos (precipitaciones anuales 


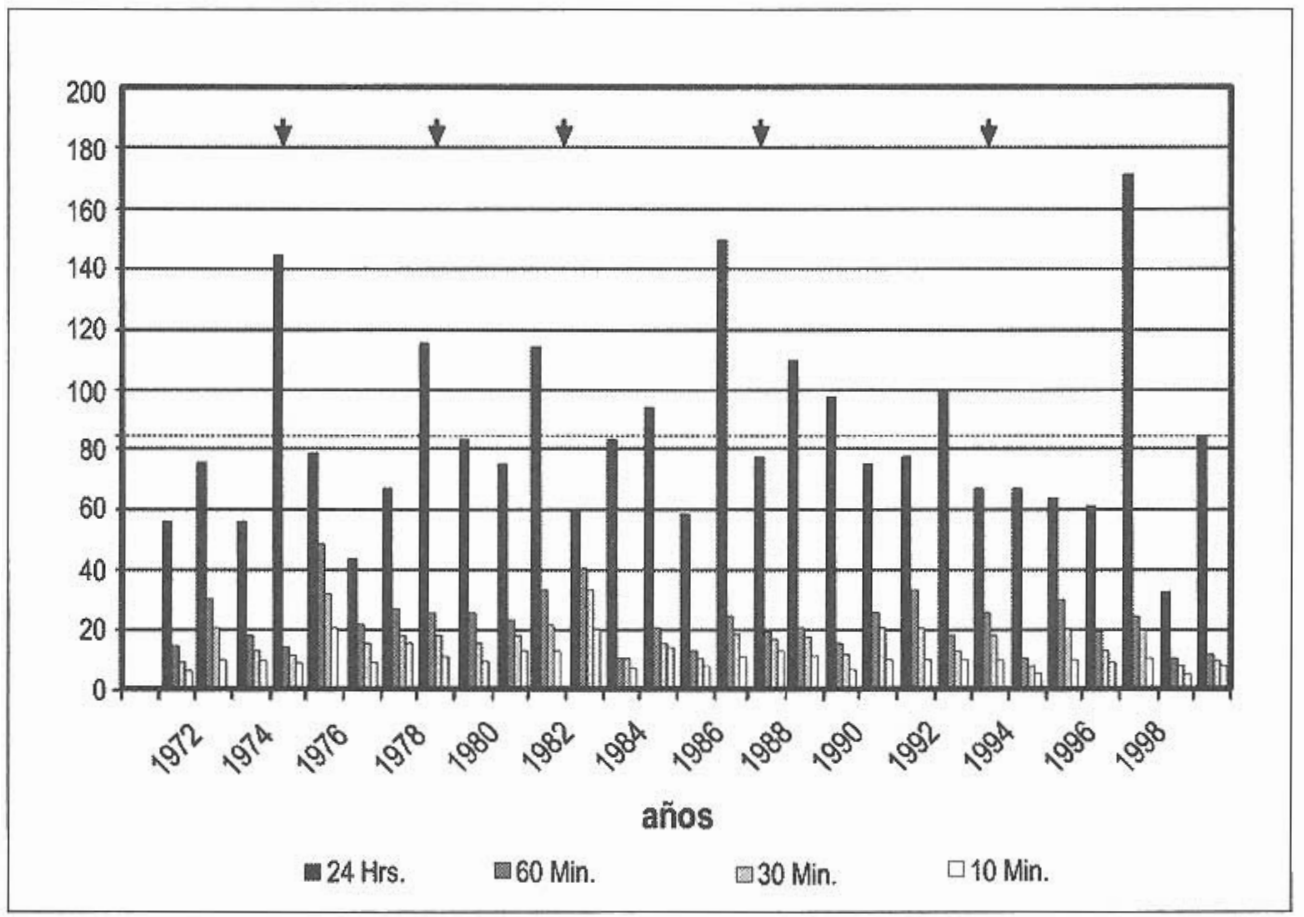

Fuente datos: Estación Metereológica Bellavista - Depto. Geofísica - U de C

Fig. 7 Intensidad de Precipitaciones en 24 hrs, 60, 30 y 10 minutos. Estación Metereológica Bellavista, 1971 - 1999

(La flecha indica años cpn desastres asociados a la lluvia; la línea punteada corrsponde a la intensidad máxima media en 24 horas)

\begin{tabular}{|c|c|c|c|c|c|c|c|c|}
\hline \multirow[b]{3}{*}{ año } & \multirow[b]{3}{*}{ mes } & \multicolumn{6}{|c|}{ Duración de las precipitaciones } & \multirow{3}{*}{$\begin{array}{l}\text { Total } 3 \text { dias } \\
\text { acumulados } \\
\text { en } \mathrm{mm}\end{array}$} \\
\hline & & \multicolumn{2}{|c|}{$1^{\circ} \mathrm{dia}$} & \multicolumn{2}{|c|}{$2^{\circ} \mathrm{dila}$} & \multicolumn{2}{|c|}{$3^{0}$ día } & \\
\hline & & fecha & $\mathrm{mm}$ & fecha & $\mathrm{mm}$ & fecha & $\mathrm{mm}$ & \\
\hline 1972 & mayo & 126 & 69.5 & 27 & 53.2 & 28 & 25.4 & 148.1물 \\
\hline 1972 & junio & 12 & 40.7 & 13 & 75.2 & 14 & 8.8 & $124.7 \mathrm{O}$ \\
\hline 1974 & junio & 24 & 44.1 & 25 & 54.2 & 26 & 143.9 & 242.20 \\
\hline 1978 & julio & 12 & 60.9 & 13 & 86.0 & 14 & 2.1 & 149.00 \\
\hline 1978 & julio & 17 & 115.7 & 18 & 32.0 & 19 & 31.0 & 178.70 \\
\hline 1981 & mayo & 4 & 49.3 & 5 & 8.5 & 6 & 115.2 & 173.00 \\
\hline 1986 & noviembre & 24 & 20.0 & 25 & 148.9 & 26 & 8.9 & 177.8 믈 \\
\hline 1988 & julio & 26 & 27.1 & 27 & 109.8 & 28 & 19.2 & 156.1뭄 \\
\hline 1992 & mayo & 2 & 52.9 & 3 & 100.1 & 4 & 42.4 & 195.4 므 \\
\hline
\end{tabular}

evento Niño año normal o próximo a lo normal

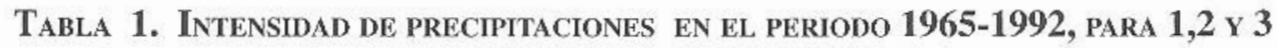
días consecutivos. Estación Meteorológica Bellavista-Concepción. 
sobre $1500 \mathrm{~mm}$ ) y sólo éstos se relacionan con la ocurrencia del Niño.

Igual variabilidad se observa en la intensidad máxima de lluvia en $24 \mathrm{hrs}$. El promedio de la intensidad máxima de lluvia diaria del periodo $1971-99$ es de $83 \mathrm{~mm}$; se presentan 7 eventos con más de $100 \mathrm{~mm}, 3$ con más de $140 \mathrm{~mm}$ y 1 con más de $160 \mathrm{~mm} / 24 \mathrm{hrs}$ (Fig. 7). De esto sólo 4 de los 7 casos se relacionan con el fenómeno del Niño. Estas máximas intensidades de lluvia detonan procesos de remoción en masa, inundaciones y anegamientos en numerosos puntos de la ciudad, especialmente si son registradas en invierno (Fig.7), cuando el suelo está saturado

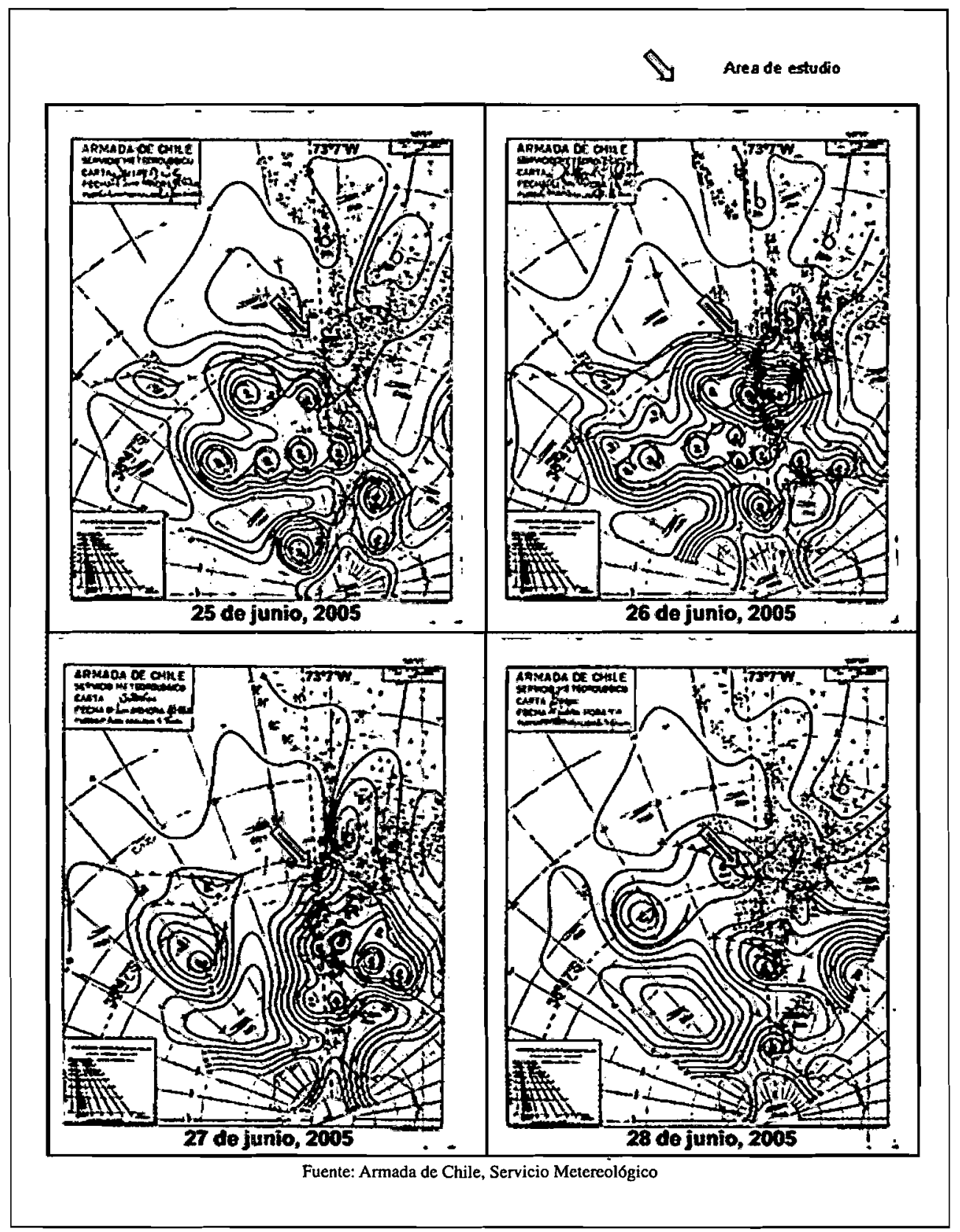

Fig. 8. Carta Sinóptica de Chile 25 al 28 de junio del 2005 
y los cauces fluviales llenos, como lo han probado los estudios realizados por Alarcón (1995), Essmann (1997), Sanhueza y Vidal (1996) y Flores (1993). Se constata la ocurrencia de episodios lluviosos sin efectos desastrosos en agosto del 2002 (135mm en $36 \mathrm{hrs}$ ), bajo la influencia de un Niño débil y en noviembre de 1997 (171,7mm/24hrs) bajo los efectos de un Niño intenso. Este último, no produjo desastres, dado que ocurrió a mediados de primavera con los suelos y los lechos relativamente secos y con una gran capacidad de infiltración y almacenamiento de agua.

Las intensidades para 60, 30 y 10 minutos, tomadas aisladamente no tienen mayor significado para la generación de desastres. Se destacan 2 casos con intensidades de precipitaciones igual o superiores a $40 \mathrm{~mm}$ en 60 minutos, en los años 1975 y 1982, independientemente del fenómeno ENOS.

Puede observarse también una acumulación extraordinaria de lluvia para periodos de tiempo mayor. La Tabla $\mathrm{N}^{\circ} 1$ sistematiza la intensidad pluviométrica para 3 días consecutivos en Concepción (1965-1992); se han seleccionado exclusivamente los eventos asociados a desastres naturales. De los 7 años registrados sólo 4 se vinculan al evento Niño.

\section{3.-El Sistema frontal del 26 de junio del 2005}

El día 25 de junio del 2005 a las $18 \mathrm{hrs}$ la carta sinóptica (Fig. 8) muestra un enjambre de ciclones asociados a una sucesión de frentes fríos desplazándose desde el océano hacia el continente, en dirección SSW-NNE. Concepción se encuentra en una situación prefrontal fría con presiones cercanas a $1016 \mathrm{mb}$. A las 2 de la mañana del 26 de ju- nio, la presión desciende progresivamente anunciando la llegada del frente para alcanzar un mínimo cercano al los $1006 \mathrm{mb}$ entre las 18.00 y las $23 \mathrm{hrs}$. del mismo día. La carta sinóptica confirma la presencia de un frente emplazado a la latitud de Concepción acompañado de un gran núcleo ciclonal, con un fuerte gradiente de presión afectando la Región del Biobío. El día 27, Concepción se encuentra en una situación postfrontal, la presión atmosférica aumenta progresivamente hasta alcanzar $1014 \mathrm{mb}$; los ciclones se han desplazado a la vertiente atlántica. El día 28 el frente se ha ocluido.

La Fig. 9 permite visualizar el desarrollo del evento pluviométrico en la ciudad de Talcahuano. Llueve continuamente durante 20 hrs. entre las 8 de la mañana del 26 de junio hasta las 3 de la mañana del 27. La precipitación se inicia suavemente a las 8 A.M., alcanzando un primer máximo de intensidad de $10 \mathrm{~mm} / 60$ minutos a mediodía; luego disminuye progresivamente la intensidad a $4 \mathrm{~mm} / 60$ minutos a las $19 \mathrm{hrs}$. y entre las $21 \mathrm{y}$ $23 \mathrm{hrs}$. alcanza el máximo de intensidad de aproximadamente $40 \mathrm{~mm}$. en $3 \mathrm{hrs}$. Continúa la lluvia intensa hasta la 1 A.M. del día 27 para retraerse progresivamente hasta finalizar el evento a las 3 de la madrugada. Fue un día de lluvia de gran magnitud: precipitaron $144.78 \mathrm{~mm}$ en las $20 \mathrm{hrs}$. de lluvia continua, en Talcahuano. Para comprender el efecto de este proceso meteorológico en la población y en el medio natural es importante agregar que durante todo el mes hubo lluvias intermitentes, algunas de gran intensidad diaria, como las ocurridas los días 6 y 17 de junio que alcanzaron una intensidad cercana a $50 \mathrm{~mm} / 24 \mathrm{hrs}$. Entre el 1 y el 25 de junio, etapa previa al evento investigado, la lluvia acumulada alcanzó $174.65 \mathrm{~mm}$, cantidad de agua suficiente para saturar los suelos y llenar los cauces fluviales. 


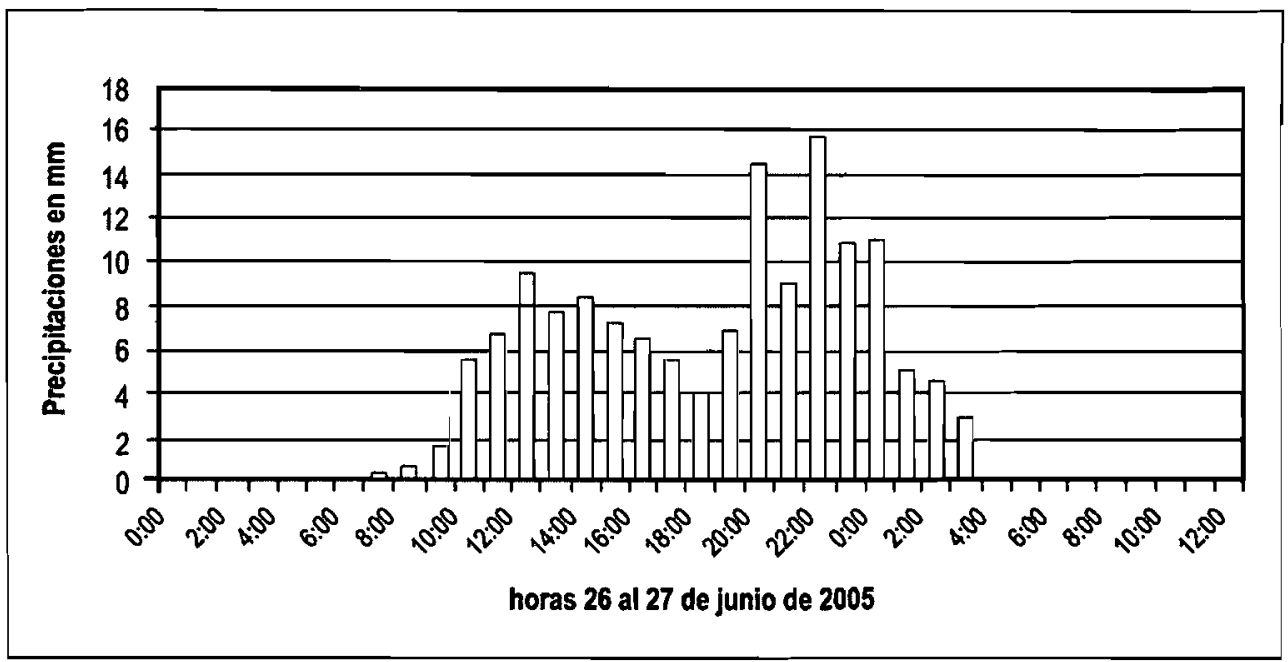

Fuente datos: INPESCA

Fig. 9. Intensidad de precipitaciones cada 60 minutos en Talcahuano, 26-27-06-2005

\section{II.- LOS DESASTRES ASOCIADOS AL EVENTO PLUVIOMÉTRICO DEL 26 DE JUNIO DEL 2005 EN EL AREA METROPOLITANA DE CONCEPCION}

\section{1.-Los Procesos Naturales: Remoción En Masa, Anegamientos, Inundaciones}

La precipitación del 26 de junio que alcanzó en $20 \mathrm{hrs}$ el monto de $158.2 \mathrm{~mm}$ en Concepción y $144.78 \mathrm{~mm}$ en Talcahuano, al agregarse a los $174.65 \mathrm{~mm}$ precipitados entre el 1 y el 25 de junio del 2005 , detonaron una cadena de procesos desastrosos en el área investigada y en toda la Región del Biobío.

En la comuna de Chiguayante (Fig. 10), hubo tres tipos de procesos: inundación producida por el desbordamiento del canal Papen, anegamientos en los sectores deprimidos y procesos de remoción en masa en las laderas de los cerros. Durante la inundación, el nivel del agua del canal alcanzo $1,6 \mathrm{~m}$ sobre el suelo afectando principalmente las poblaciones Los Boldos y Villa Antuco. La insuficiencia de sistemas de drenaje de aguas lluvia, la falta de capacidad de evacuación y de mantención de éstos y la disponibilidad de sedimentos acumulados por la construcción de BIOVIAS (Empresa de Ferrocarriles de la Intercomuna) serían factores que contribuyeron al desborde del canal y a la generación de anegamientos. Los procesos de remoción en masa variaron dependiendo del contenido de agua, entre derrumbes y flujos de barro. Estos atacan las laderas de los cordones de la Cordillera de la Costa, conformados por granito de edad paleozoica con un manto meteorizado de "maicillo" que puede alcanzar potencias $>10 \mathrm{~m}$. La incorporación del agua a los materiales de baja compacidad induce a una pérdida de resistencia de los materiales comprometidos, produciendose primero un desprendimiento; luego, en virtud de la pendiente $\left(>30^{\circ}\right)$ y de la incorporación de materiales incoherentes saturados de agua, se generan flujos de barro que se canalizan por estructuras de porteo identificadas como líneas de drenaje intermitente de orden 1 a 2. Al llegar a la planicie los sedimentos aluvionales se depositan afectando a la población emplazada sea en la ciudad de Chiguayante o en los sectores bajos de las quebradas de la comuna. En las Figs. 11 y 12 se muestra uno de los flujos; la Municipalidad de Chiguayante debió extraer desde las calles de la ciudad más de $750 \mathrm{~m} 3$ de barro conformado por arcilla, maicillo y algunos bloques de roca granítica. 


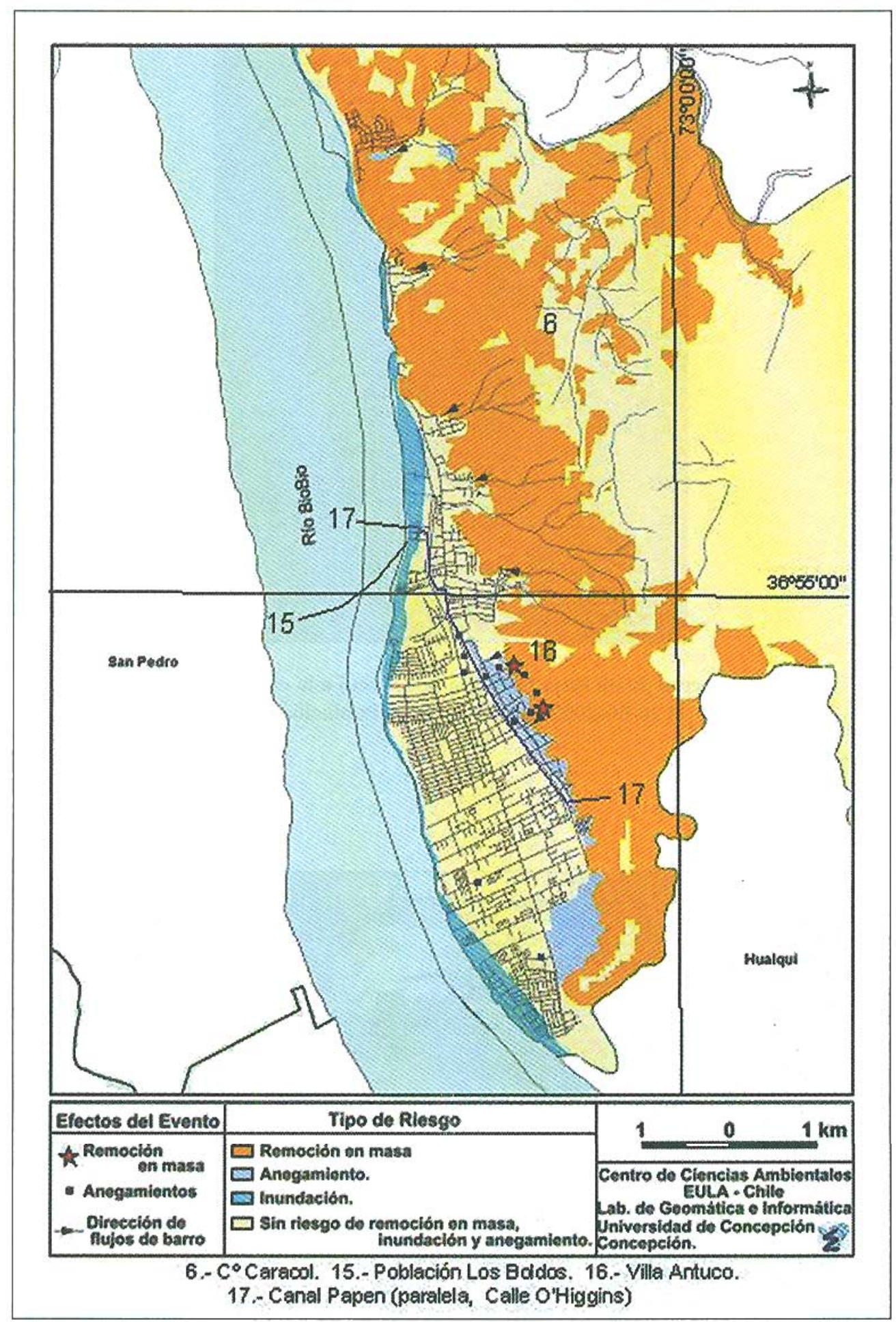

Fig. 10. Sectores Afectados por el evento pluviométrico del 26-06-05 Comuna de Chuguayante

(datos recopilados por el autor) 


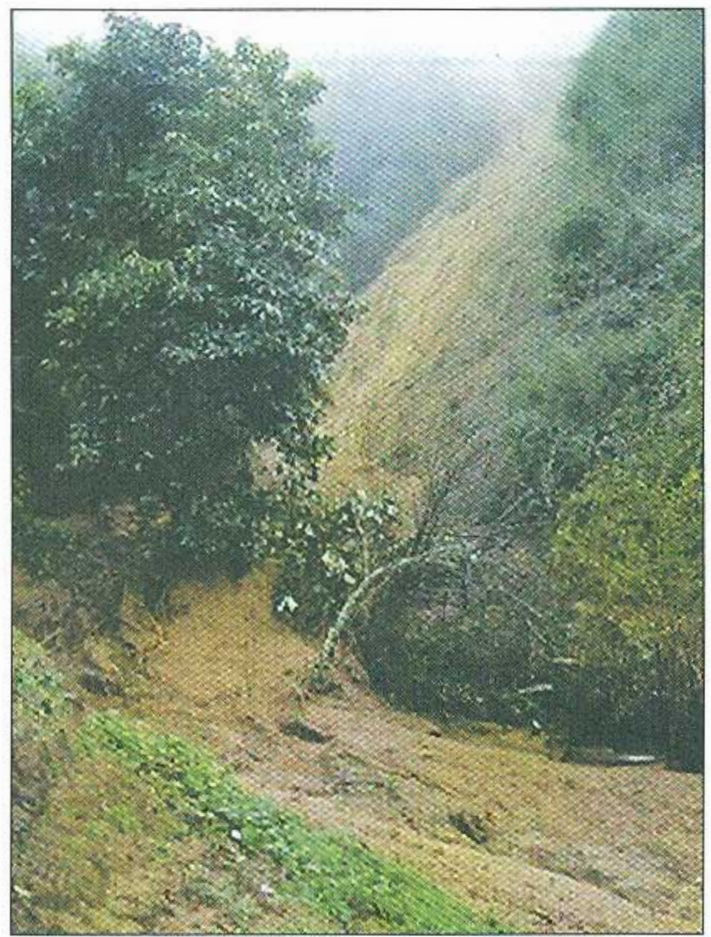

Fig. 11. Cabecera de un flujo de barro que afectó a la ciudad de Chiguayante el 26-06-2005, sector superior Población Papen.

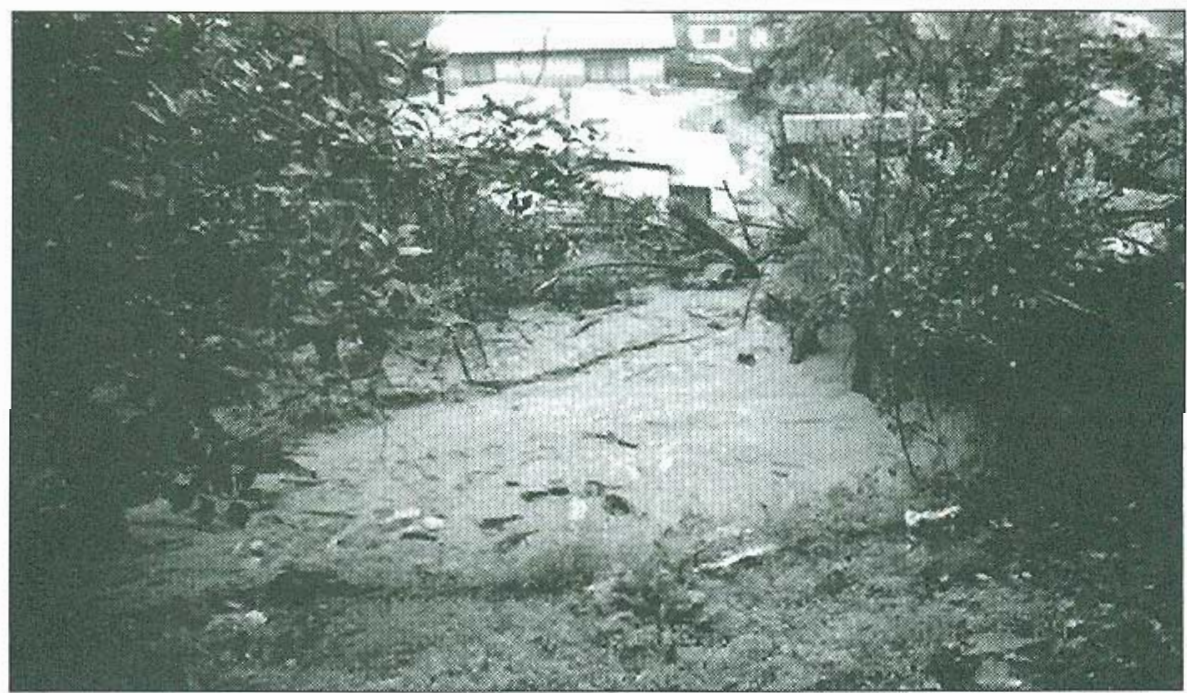

Fig. 12. Población Papen afectada por la depositación de un flujo de barro procedente de las laderas de los cordones de granito paleozoico. Proceso de remoción en masa generado por el evento pluviométrico del 26-06-2005. 
En la comuna de Concepción (Fig. 13) los procesos más graves fueron: la inundación producida por el desborde del Estero Nonguén y los procesos de remoción en masa de los Cerros La Pólvora y sector Agüita de La Perdiz (emplazado al S del Barrio Universitario). De acuerdo a entrevista realizada a los vecinos, el desborde del Estero Nonguén se inició a las 22.30 hrs. del 26 de junio, 30 minutos después del máximo de precipitación; el peak de descarga ocurre a la medianoche del mismo día. El nivel del estero asciende de 2 a $3 \mathrm{~m}$ de altura en relación a su nivel normal, inunda toda la llanura inferior de su curso y afecta a más de 300 familias e infraestructuras allí emplazadas (Valle Nonguén, sector Collao, Universidad del Biobío).

El Estero Nonguén es una subcuenca del río Andalién (775 km2), tiene una extensión de $50 \mathrm{~km} 2$ y posee una captación manejada por ESSBIO (empresa de agua potable de la zona) para producir agua para la comuna de Penco y parte de la comuna de Concepción, con un caudal de abastecimiento aproximado de 6,9 millones de litros diarios. Esta es una cuenca con régimen hidrológico pluvial, hasta 1997 estabilizada morfogenéticamente considerando que presentaba un índice de cobertura vegetal superior al $75 \%$ (Jaque, 1997); no obstante, dominan rangos de pendiente entre 12 y $27^{\circ}$, lo que la expone a riesgo de procesos de remoción en masa y a altas tasas de escorrentía superficial en caso de disminuir dichos rangos de cobertura. Mardones et al. (1994), constataron que con umbrales de pendiente superiores a $20^{\circ}$ y coberturas vegetales inferiores a $50 \%$, el granito meteorizado tiene alto riesgo de procesos de remoción en masa si la intensidad de precipitación diaria supera los $100 \mathrm{~mm}$. Explicar la descarga rápida del Estero del Nonguén es por tanto más complejo: a la intensidad de lluvia diaria se debe anexar la saturación del suelo por la lluvia continua recibida en el periodo precedente al evento; la tala de bosques experimentada desde el año 1997 a la fecha lo que disminuye su cobertura y aumenta la erosión del suelo; el incremento de caudal del colector principal (río Andalién) que a causa de las preci- pitaciones subió su nivel en $5 \mathrm{~m}$ en la llanura de Concepción-sector Santa Clara (Diario El Sur 28-06-2005), generando una obstrucción a la descarga del Estero Nonguén y finalmente, según opinión de los vecinos, el desborde del sector de captación de ESSBIO. Numerosos sectores de la llanura del Andalién también fueron inundados, por la crecida inusual de este río que, tal como se aprecia en la Fig. 14 , sobrepasa ampliamente su caudal medio mensual en los meses de junio y julio del 2005.

Inundaciones también ocurren en las riberas de las lagunas que pueblan la llanura de Concepción, y muy especialmente en la Laguna Las Tres Pascualas cuyo espejo de agua ascendió más de $2.5 \mathrm{~m}$ sobre su nivel medio, llegando al borde de la calle Paicaví, principal arteria que conecta Concepción y Talcahuano.

Los procesos de remoción en masa más violentos se produjeron en el sector Agüita de la Perdiz, cuyas condiciones litológicas y morfológicas se asemejan a las descritas para Chiguayante; éste ha sido progresivamente colonizado por poblaciones vulnerables, desde la segunda década del siglo XX. Este sector corresponde a una pequeña quebrada emplazada en las laderas de la Cordillera de la Costa, conformadas por granito de edad Paleozoica con un manto meteorizado que puede superar los $27 \mathrm{~m}$ de potencia con gran cantidad de cristales de cuarzo ("maicillo"). $\mathrm{Su}$ análisis mediante difracción de Rayos-X revela la presencia de arcillas del tipo Halloysita $7 \AA$, Illita y Clinocloro. El primer tipo es el más importante, ya que es una arcilla de composición química y estructura similar a las caolinitas, expandible y puede hidratarse hasta conformar Halloysita $10 \AA$. El flujo de barro dejó una corona con un perímetro de $22,4 \mathrm{~m}, 2 \mathrm{~m}$ de alto y $7,2 \mathrm{~m}$ de ancho, así como un cono de $24 \mathrm{~m}$ de largo, compuesto por dos tramos de igual longitud: uno superior con una pendiente de $35^{\circ}$ y uno inferior con $25^{\circ}$ de pendiente, ambos aún inestables. Además, en él se observa un canal central por donde fluye agua que aflora en el cambio de pendiente y numerosos boulders 


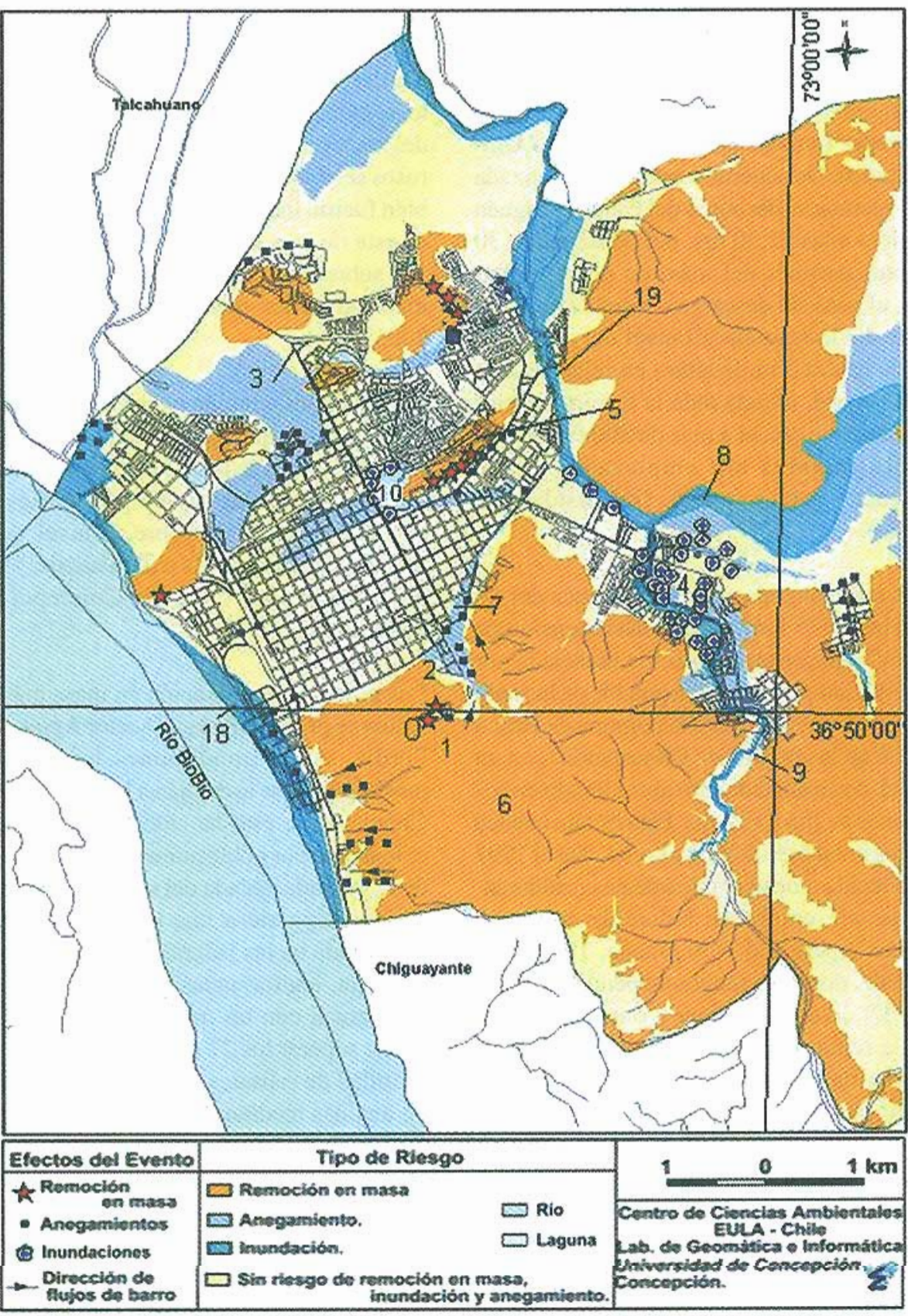

1. Aquita de la Perdz. 2.- Barrio Universitario. 3. C alle Paicari. 4. Valle Nonguén, C ollao y UBB. 5. $\mathrm{C}^{\circ} \mathrm{La}$ Polvora. 6. $\mathrm{C}^{\circ} \mathrm{C}$ aracol. 7. Llanura Hospital. 8. Río Andalien. 9. Est $\mathrm{N}$ onguen.

10. Laguna Las tres Pascualas. 18. Ribera N orte. 19.- Llanura C oncepción, sector Santa Clata

Fig. 13. Sectores Afectados por el evento pluviométrico del 26-06-05. Comuna de Concepción

(Datos recopilados por el autor) 


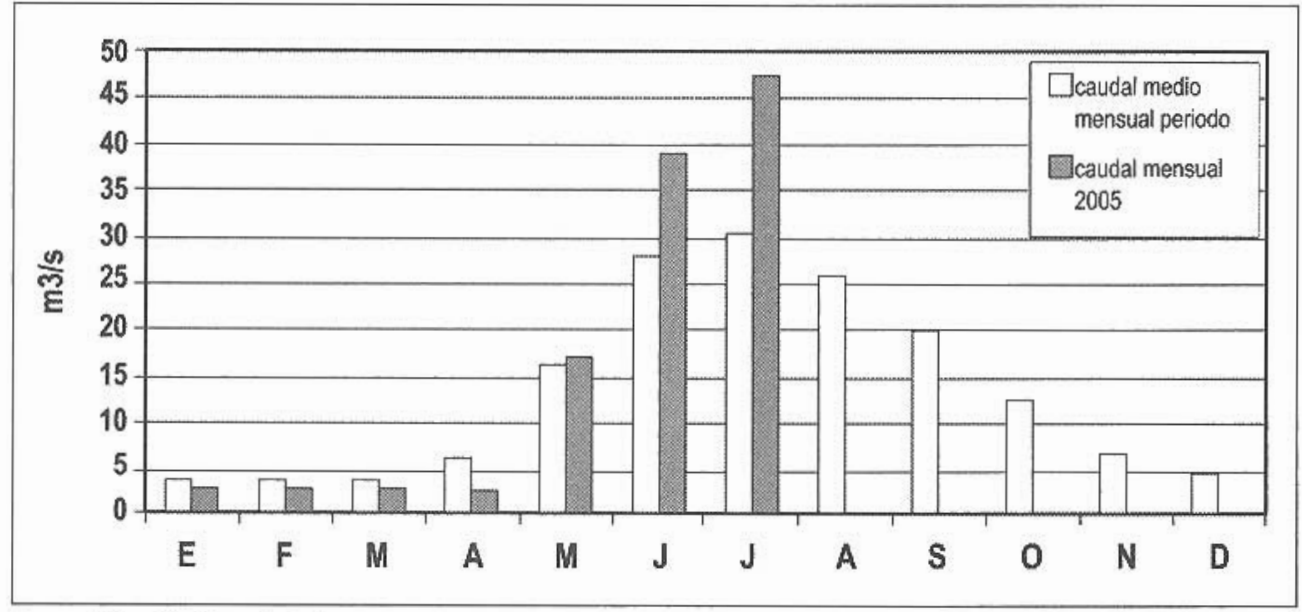

Fuente : Dirección General de Aguas

Fig. 14. Caudales medios mensuales del río Andalién periodo 1961 - 2005 versus caudales mensuales del año 2005

(datos II semestre 2005 no aportados por DGA)

de granito muy meteorizado, de diámetro entre 0,4 y $1,5 \mathrm{~m}$.

Entrevistas realizadas a los vecinos señalan que se produjo una gran flujo de barro en la cabecera de la quebrada que desplazó por decenas de metros a 2 viviendas, destruyéndolas (Fig. 15) y otros tres derrumbes que arrasaron igualmente las habitaciones que encontraron a su paso. Estos procesos se detonaron entre las 19 y 22 hrs. El alud de barro llegó a la calle principal pavimentada (calle Yerbas Buenas), con una pendiente media superior a $15^{\circ}$ (Fig. 16), donde el agua alcanzó más de medio metro de altura, formando un aluvión que siguió su curso hasta llegar a la llanura (Barrio Universitario) que fue inundada por un alud de $1 \mathrm{~m}$ de barro y agua. Estos procesos se detonaron entre las 19 hrs y 22 hrs, durante el lapso de la máxima intensidad de lluvia, dejando 90 casas gravemente afectadas, algunas completamente destruidas y 1 víctima fatal. Los factores más importantes asociados a estos procesos son: la fuerte pendiente topográfica que en condiciones naturales puede sobrepasar los $30^{\circ}$ y la eliminación del confinamiento natural producido por el socavamiento de las laderas para emplazar las viviendas, lo que aumenta el umbral de pendiente en algunos casos a cerca de $45^{\circ}$.
El Cerro La Pólvora está conformado principalmente por rocas sedimentarias de edad Terciaria, con manteos de $16^{\circ}$ a $20^{\circ} \mathrm{NW}$, las que se sobreponen en inconformidad a las rocas graníticas de edad Paleozoica. Ambas unidades se encuentran profundamente alteradas; Galli (1967) estima un promedio de $7 \mathrm{~m}$ de espesor de suelo arcilloso par los cerros isla de Concepción. La ladera SE corresponde a un escarpe de falla con actitud $\mathrm{N} 45^{\circ} \mathrm{E} / \mathrm{SE}$, con pendientes topográficas sobre $30^{\circ}$, en la cual el evento pluviométrico del 26 de junio detonó cuatro derrumbes entre las 19 y 21 hrs. Los cuatro procesos se extendieron a poca distancia de la ladera del cerro; el de mayor alcance cubrió un recorrido horizontal de $15 \mathrm{~m}$ (Fig. 17). De éstos, 2 derrumbes se desarrollaron en el afloramiento de granito construyendo conos con pendientes de $30^{\circ}$ y de $47^{\circ}$. De la corona de uno de ellos se recuperó material conteniendo arcillas similares a las encontradas en el sector Agüita de la Perdiz, lo que confirmaría la presencia de granito meteorizado. En un tercer cono de derrumbe, con pendientes de $45^{\circ}$, se encontró material diferente al anterior, sin cristales de cuarzo y de una coloración amarillenta. El análisis de difracción de Rayos- $X$ reveló abundante Nontronita, además de Clinocloro, Illita y Halloysita $7 \AA$. . Se presume que estas arcillas provienen de 


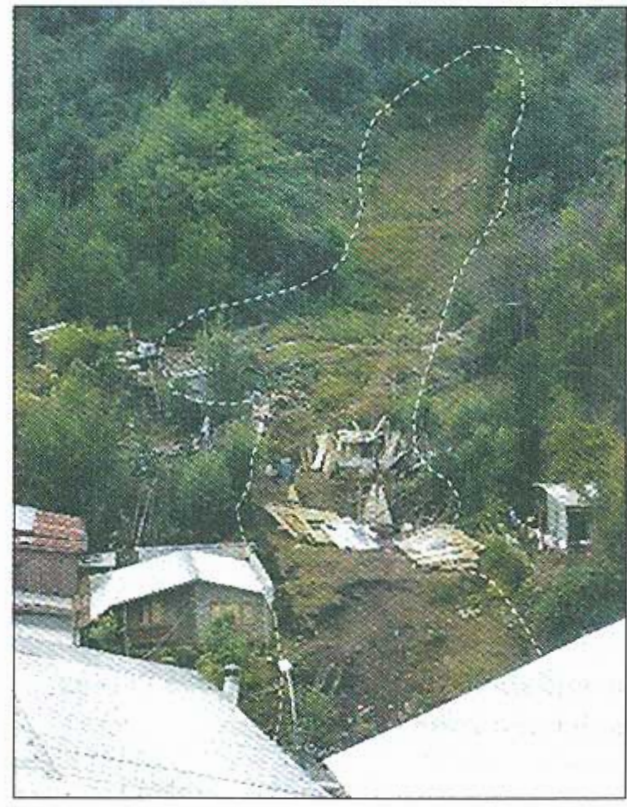

Fig. 15. Huellas del flujo de barro que se produjo en la cabecera de la quebrada Agüita de la Perdiz, casi un año después. Foto: 24-04-2006

la meteorización de las rocas sedimentarias de edad Terciaria. La nontronita es una esmectita férrica, con una alta expandibilidad al absorber agua (el espesor de las capas puede aumentar de $9,7 \AA$ a $17,4 \AA$ ); por otra parte, a diferencia de la Halloysita, requiere de un mayor aporte energético para perder el agua que absorbieron, lo que puede favorecer la continuidad del movimiento del flujo una vez producido el primer desplome.

En la Comuna de Talcahuano, particularmen-

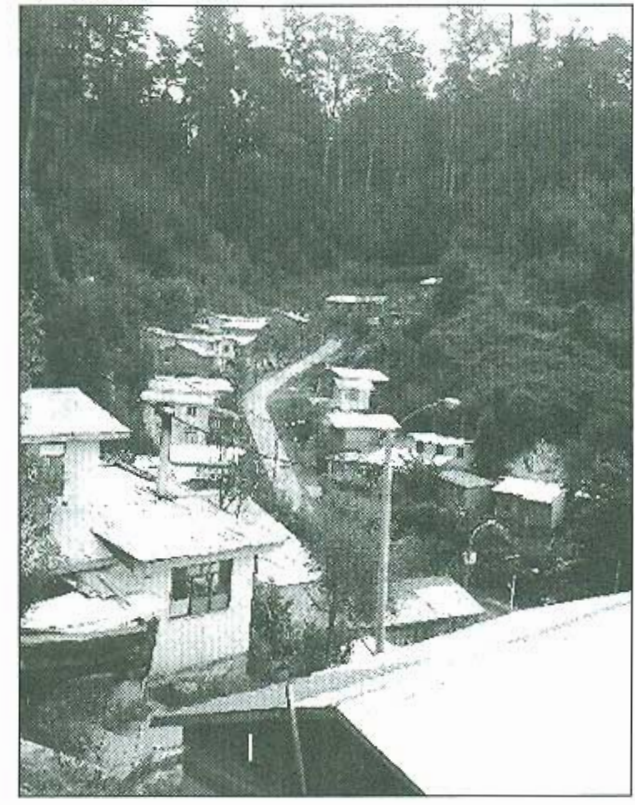

Fig. 16. Población Agüita de la Perdiz. Al fondo calle Yerbas Buenas, que canalizó el flujo de barro y el agua de escorrentía superficial aportada por la lluvia del 2706-2005. Foto 24-04-2006

te en las laderas de los cerros de la Península de Tumbes, se produjeron numerosos procesos de remoción en masa (derrumbes y flujos de barro) que dejaron un muerto y 60 casas con daños importantes (entre las cuales 36 fueron completamente destruidas). El mayor desastre en la comuna estuvo relacionado con los anegamientos. Estos se produjeron principalmente en los sectores bajos asociados a paleocanales fluviales y marismas que han sido rellenadas para su ocupación (Fig. 18).

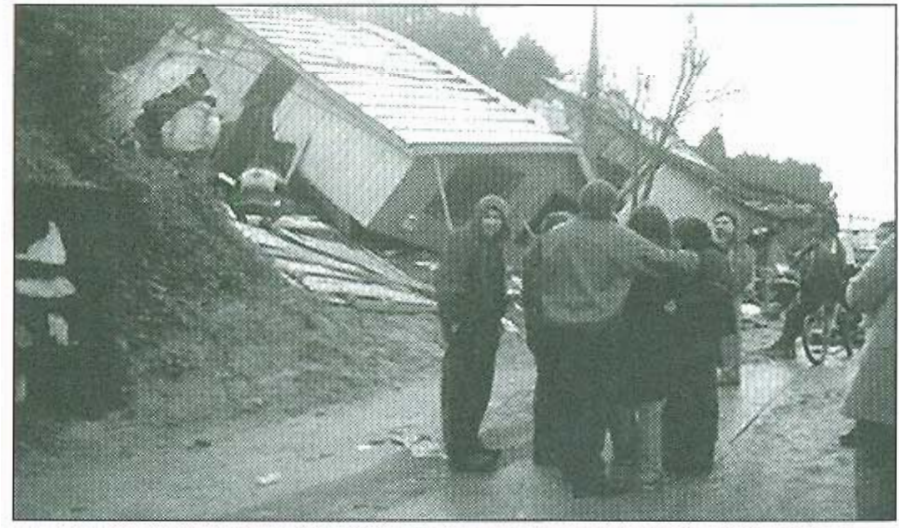

Fig. 17. Derrumbes Co

La Pólvora, calle Pelantaro. Siete familias afectadas y 3 muertos. Foto: 01-07-05 


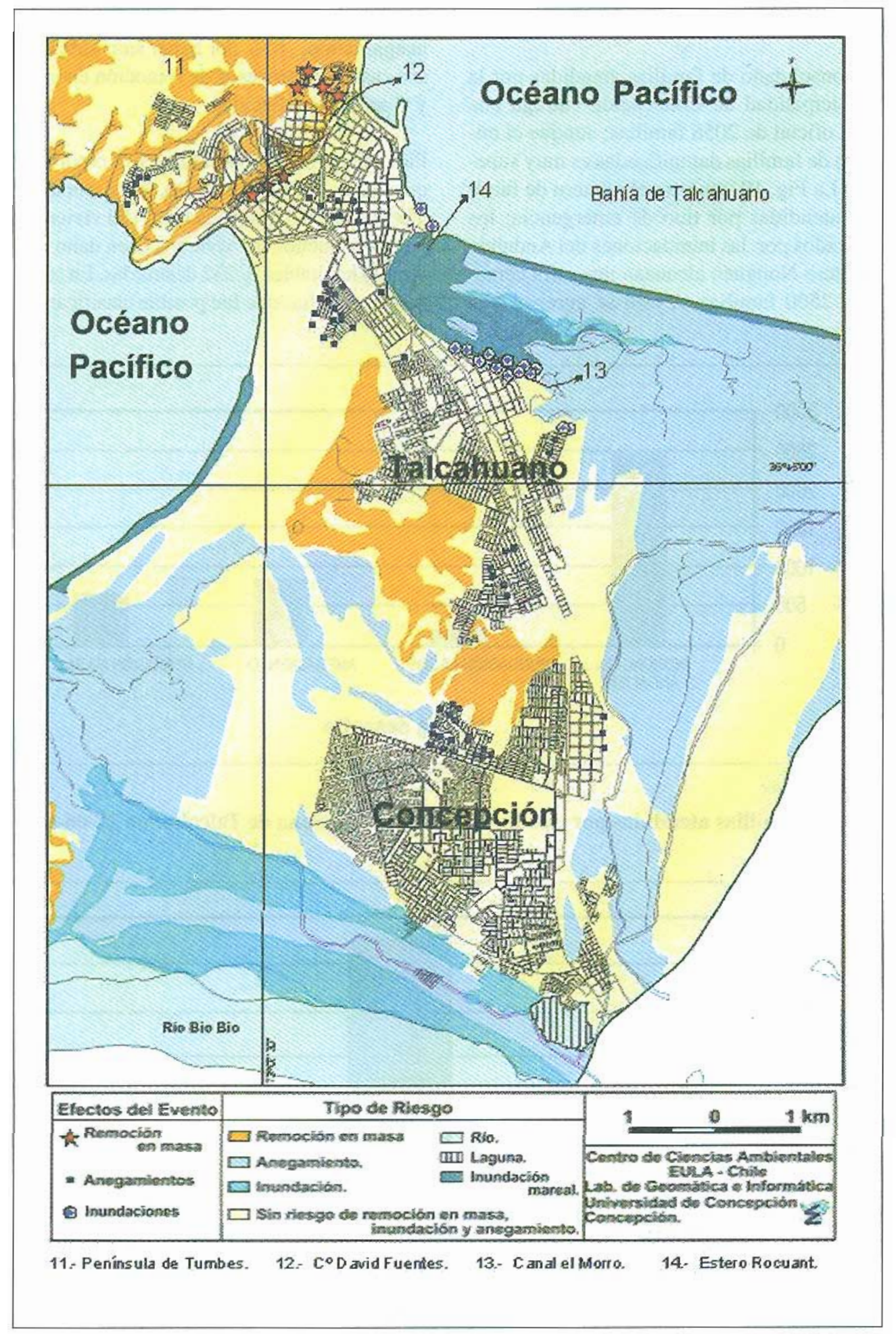

Fig. 18. Sectores Afectados por el evento pluviométrico del 26-06-05 Comuna Talcahuano

(Datos recopilados por el autor) 
Una contribución al estudio de los desastres naturales en Chile Centro Sur

\section{2.-Los efectos en la población:}

El consolidado de familias atendidas por la Municipalidad de Concepción entrega una cifra oficial de 2056 familias; aunque el número de familias damnificadas es muy superior. La Fig. 19 muestra el número de familias atendidas por tipo de emergencia; los afectados por las inundaciones del Andalién y Estero Nonguén alcanzan una cifra cercana a 2500 familias. A esto se agregan 804 familias atendidas por problemas de anegamiento, 636 por haber sido afectadas sus casas por procesos de remoción en masa y 4 personas fallecidas.

Para la comuna de Talcahuano, el reporte de ocurrencia señala 1 muerto, 8965 personas afectadas, 954 damnificados, 2183 viviendas con daño menor, 81 viviendas con daño mayor (no habitables) y 232 destruidas. En cuanto a las familias que fue posible clasificar por

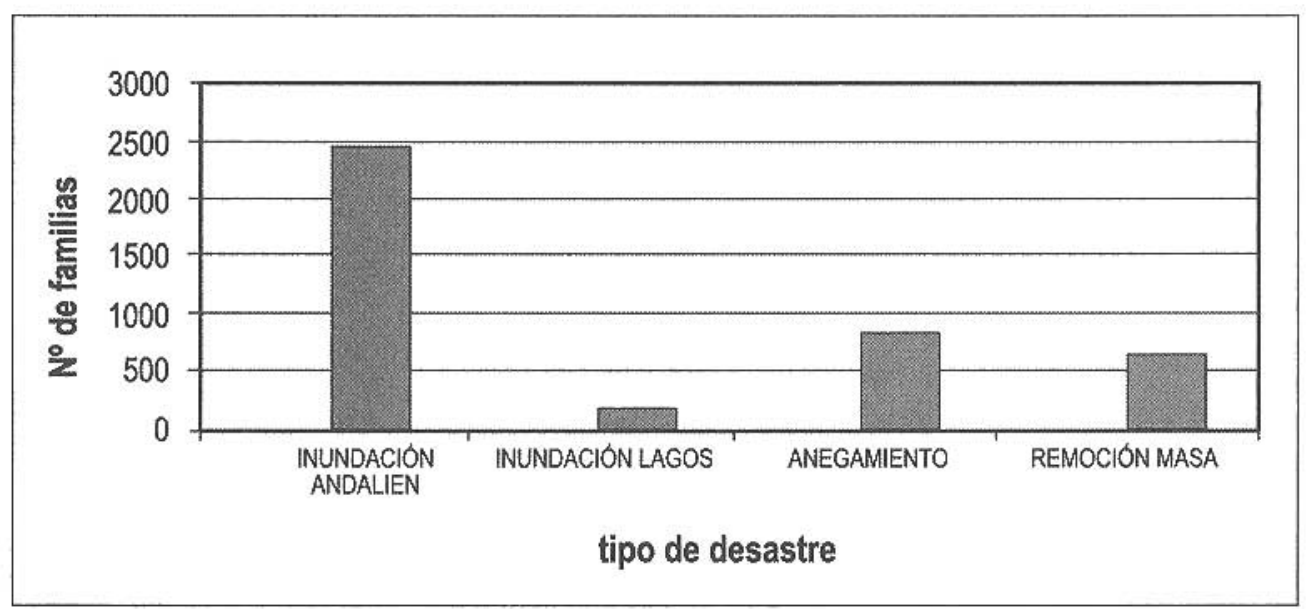

Cálculos del autor

Fig. 20. Familias atendidas por tipo de emergencia. Comuna de Talcahuano 27-06-05

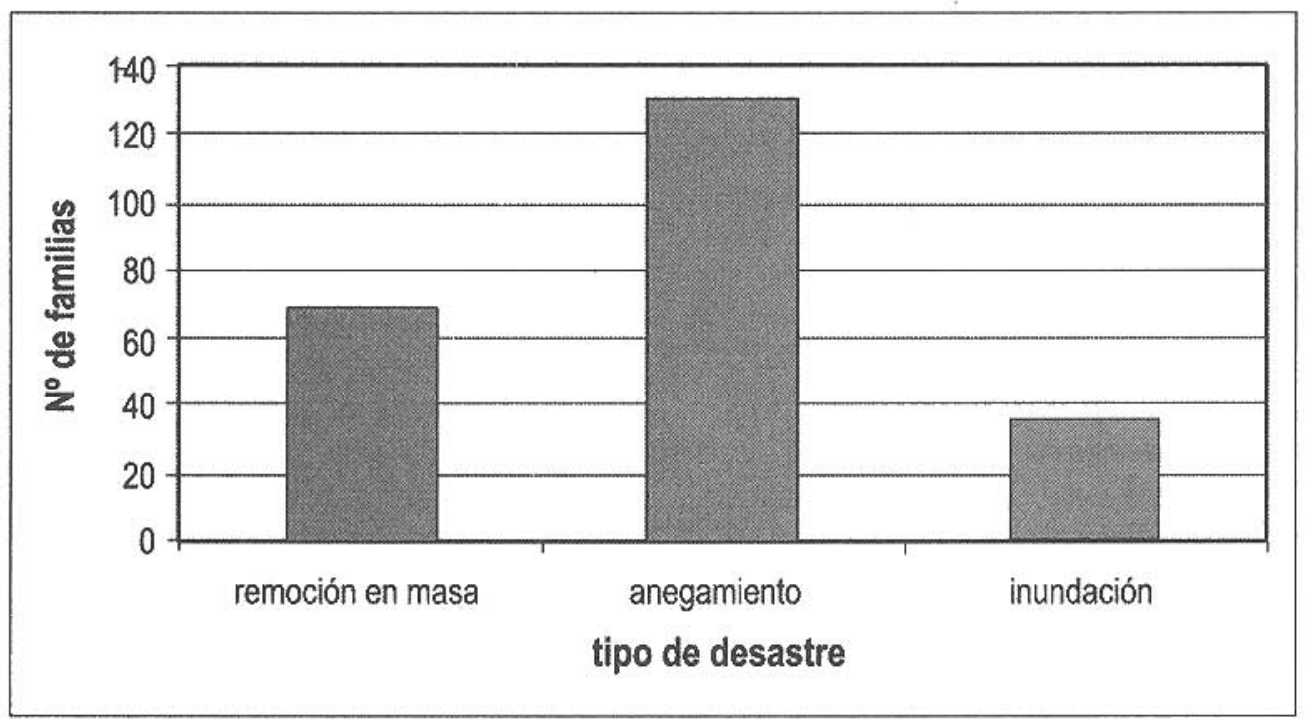

Cálculos del autor

Fig. 19. Familias atendidas por tipo de emergencia. Comuna de Concepción 27-06-05 
tipo de desastre se estiman 132 familias anegadas, 68 damnificadas por procesos de remoción en masa y 36 por inundaciones asociadas al desborde del Estero Rocuant y canal el Morro (Fig. 20).

En la comuna de Chiguayante se estiman: 1 muerto y 330 familias damnificadas; entre éstas hay 300 viviendas con daño menor, 15 con daño mayor no habitable y 15 totalmente destruidas.

Informes emanados de la Intendencia Regional señalaban el 2 de julio del 2005, que el total de damnificados para la Región del Biobío era de 27144 concentrándose el 59\% en el área metropolitana de Concepción donde se contaba un total de 15944 personas afectadas por los desastres y 381 viviendas destruidas.

El costo del desastre a nivel regional fue de acuerdo a datos aportados por OREMI, de 3.761.067.414 pesos. El 84.4\% de este monto fue aportado para reparación y mantención de la infraestructura vial; apenas un $4.11 \%$ se destinó a solucionar los problemas de vivienda (vía Chile Barrios) y $1.44 \%$ para la conservación, limpieza y recuperación de los sistemas de drenaje de aguas lluvia.

\section{DISCUSION Y CONCLUSIONES}

El evento pluviométrico que afectó el litoral de Concepción el 26-06 del 2005 consistió en una lluvia continua durante $20 \mathrm{hrs}$ que acumuló un monto de $144.78 \mathrm{~mm}$ en la comuna de Talcahuano y $158.2 \mathrm{~mm}$ en Concepción, con un máximo de intensidad entre las 21 y $23 \mathrm{hrs}$, que ocasionó efectos desastrosos en la población dejando en el área investigada un total de 5224 damnificados, 36 casa destruidas y 5 personas muertas.

Este es un día de lluvia geográfica y ambientalmente significativo, pues permite detectar los sectores vulnerables al riesgo de inundación, anegamiento y procesos de remoción en masa, así como los umbrales de precipitación capaces de detonar en cadena este tipo de procesos. La magnitud de los daños fue proporcional a la intensidad del meteoro, aunque el impacto fue espacial y socialmente diferenciado, ya que afectó particularmente a los sectores más pobres de la ciudad y expone una serie de problemas asociados a la falta de previsión y de planificación.

Esta investigación confirma las conclusiones de Mardones et al. (1994) y Mardones y Vidal (2001) en relación a que los umbrales de precipitación superiores a $100 \mathrm{~mm}$ en $24 \mathrm{hrs}$ son capaces de detonar catástrofes, con efectos graves si la intensidad es superior a $150 \mathrm{~mm} /$ $24 \mathrm{hrs}$. Intensidades de lluvia de esta magnitud (igual o superior a $150 \mathrm{~mm} / 24 \mathrm{hrs}$ ) tienen periodos de recurrencia de aproximadamente 20 años y una probabilidad de ocurrencia anual de $5 \%$. Se han presentado 2 casos entre 1965 y el 2005, de los cuales únicamente el evento de junio del 2005 ocasionó desastres, ya que el episodio lluvioso del año 1997 se desarrolló en el mes de noviembre, con suelos y redes de drenaje con capacidad de almacenaje de agua. Periodos de recurrencia semejante han sido estimados por Alarcón (1995), quien a través de un estudio de los desastres ocurridos en el área metropolitana de Concepción en el periodo 1960-1990, concluye que procesos de remoción en masa afectando a más de 13 familias y de inundación a más de 298 familias, tienen periodos de recurrencia $\geq 20$ años. Se constatan desastres para intensidades diarias menores, pero éstas estarían relacionadas con la acumulación de un monto pluviométrico $\geq 150 \mathrm{~mm}$ en tres días consecutivos. Sólo el $43 \%$ de las lluvias que presentaron intensidades $\geq$ $100 \mathrm{~mm} / 24 \mathrm{hrs}$ se produjeron bajo el efecto del fenómeno del Niño; mientras que el $56 \%$ de aquellas que se produjeron por la acumulación de lluvia en 3 días consecutivos se generaron bajo esta condición.

Por otra parte, este trabajo constató que los desastres se distribuyeron en las áreas previamente definidas como sectores de peligrosidad por Mardones et al.(1994) y Mardones 
y Vidal (2001), las que aparecen cartografiadas en las Figs. 10, 13 y 18. Las zonas que confirman su peligrosidad frente a procesos de remoción en masa son: en Talcahuano las laderas orientales de la Península de Tumbes; en Concepción las laderas de los cerros Caracol y cerros-isla, particularmente aquellas intervenidas con una gran carga poblacional vulnerable (Co $\mathrm{La}$ Pólvora) y las laderas de cerros y quebradas de la comuna de Chiguayante. Las áreas con alto riesgo de inundación fluvial se incrementan en el curso inferior del río Andalién y Estero Nonguén, en razón del crecimiento y densificación de la ciudad en dicho sector; pero disminuyen en la ribera $\mathrm{N}$ del río Biobío, debido al manejo y estabilización de la ribera. En cuanto al riesgo de anegamiento se experimenta un aumento del área expuesta, en sectores al pie de laderas afectadas por procesos de remoción en masa, en los conos aluviales de quebradas con escurrimiento epiśdico y en llanuras con poblamiento reciente, emplazado en pequeñas hondonadas, sin sistema de drenaje de aguas- lluvia.

En relación a los factores que contribuyen a generar desastres de esta magnitud y que son factores de riesgo a considerar en la planificación y gestión territorial, están los factores naturales, especialmente aquellos relacionados con la litología y morfometría de pendientes para el caso de los proceso de remoción en masa. Se confirma que laderas con pendientes $\geq 25^{\circ}$ tienen un alto grado de amenaza de deslizamientos y flujos de barro. Por otra parte, la magnitud y frecuencia de estos procesos se relacionan con el tipo y cantidad de material fragmentario disponible, de tal modo que la potencia de la alterita junto a la abundancia de nontronita y halloysita explicarían la alta peligrosidad de los escarpes estudiados. Rodine y Jonson (1976) señalan que una arcilla caolínica (tipo de arcilla abundante en el granito meteorizado de la región) pasa de estado de mezcla adhesiva con $27 \%$ de contenido de agua, a mezcla fluida con alrededor de $37 \%$ de contendido de agua; estos flujos tienen gran viscosidad y pueden transportar grandes bloques, como fue el caso del flujo de barro de Agüita de la Perdiz. Comportamiento semejante tienen las arcillas de tipo montmorillonita, cuya presencia ha sido registrada en los cerros costeros estructurados en roca sedimentaria de edad terciaria (Flores, 1993).

Pero todo indica que un conjunto de factores antrópicos se agregan a estos factores naturales, dando lugar a una serie de tensiones que favorecerían la rotura y desestabilización de taludes, tales como: la tala y quema de bosques en las cabeceras de cuenca y parte alta de las laderas, lo que reduce la coherencia del suelo; la excavación de laderas y disminución del apoyo lateral de los taludes para emplazar casas; la presencia de canales obstruidos con sedimentos y basura; la ausencia de colectores de aguas-lluvia y el desarrollo de obras (BIOVIAS) que dejan sedimentos acumulados en el suelo.

En relación a la rápida descarga fluvial del estero Nonguén, ésta se relaciona estrechamente con la duración intensidad de la tormenta y el tamaño de la cuenca. Datos aportados por Strahler (1986) indican que una cuenca pequeña de aproximadamente 0.4 $\mathrm{km} 2$, experimenta su descarga máxima 10 minutos después del máximo de lluvia; mientras que para una cuenca de $805 \mathrm{~km}^{2}$ el periodo de retardo es de 24 hrs. Si se relacionan estos datos con el periodo de retardo del Estero Nonguén (peak de descarga 2 hrs. después) se aprecia que existe una relación lineal; aunque por la ausencia de registros fluviométricos y la carencia de datos relativos a los rellenos artificiales en la parte baja de la cuenca, no se puede atribuir la magnitud y velocidad de la descarga sólo a factores naturales.

En lo que respecta a la cantidad de familias damnificadas, casas destruidas, personas fallecidas y costo del desastre, las cifras indican claramente una ocupación insustentable del territorio y la carencia de Programas de Gestión del Desastre. Ocupación insustentable dado que la ciudad se expande en áreas reconocidas como de alto riesgo de inundación, anegamiento y procesos de re- 
moción en masa y gestión inadecuada debido a que se han detectado en el caso que se investiga, los siguientes problemas:

- Sistema de alerta carente de efectividad para respuesta oportuna. La primera alerta llega desde los vecinos una vez iniciado el proceso. La mejor reacción frente a la catástrofe, se produjo en las comunidades vecinales que estaban mejor organizadas (Juntas de Vecinos de Agüita de la Perdiz).

- Falta de un programa integrado para enfrentar la emergencia

- Carencia de una estructura operativa, centralizada y funcional. Descoordinación de los organismo involucrados

- Carencia de áreas de resguardo previamente programadas y de recursos económicos de rápida disponibilidad para enfrentar la emergencia.

- Una vez que la emergencia termina, no se construye una base de datos con los conocimientos científicos adquiridos que permitan construir o perfeccionar el Programa de Gestión del.Desastre

\section{RECOMENDACIONES}

\section{Se recomienda por tanto que:}

-los sectores evaluados como de alto riesgo geomorfológico debieran ser considerados tanto en los Planes de Ordenamiento del Territorio, como en los Programas de Prevención de Desastres.

-la actualización permanente de la carta de Riesgos Naturales es un instrumento importante para el uso sostenible del territorio regional. Esto permitiría prevenir, preparar a la población para dar respuesta a un desastre y evitar pérdidas humanas y económicas. - elaborar cartas de áreas de resguardo para los diferentes tipos de catástrofes y construir vías de evacuación debidamente señalizadas; otorgando la difusión adecuada para el conocimiento de la población.

- la evaluación de la Gestión del Desastre en Concepción permite señalar que existen falencias importantes en la Planificación de la Protección Civil, a nivel local y regional. Se sugiere centralizar la gestión en la OREMI mediante un Plan de Protección Civil que tenga: unidad de dirección, coordinación de actuación, recursos permanentemente disponibles y autonomía en la ejecución y que esté directamente conectado con los Centros Científicos encargados de dar la Alarma y entregar los datos para la Prevención, Mitigación y Preparación del Desastre.

-Se sugiere un Programa de Gestión del Desastre donde los Comités Vecinales (Juntas de Vecinos) tengan un rol protagónico y preventivo y tengan el conocimiento suficiente para tener una respuesta adecuada frente a la emergencia (Fig. 21)

Considerando la vulnerabilidad de gran parte de la población de Concepción y la alta peligrosidad del sitio urbano, se espera que estos resultados contribuyan en parte a comprender la geografía y dinámica del desastre de este sector de nuestro país.

\section{AGRADECIMIENTOS}

Este trabajo fue posible gracias a los datos aportados por las siguientes instituciones $y$ personas: Directores Comunales de Emergencia de Talcahuano (Sr. Fernando Varela), Chiguayante (Sr. Henry Guzmán) y Concepción (Sr. Hugo Soto); Director de Protección Civil y Emergencia Regional Sr. Jaime Romero (OREMI); Servicio Meteorológico, Armada de Chile; Dirección Meteorológica de Chile (Aeropuerto Carriel Sur); Instituto de Investigaciones Pesqueras de Talcahuano (INPESCA); Dirección General de Aguas (DGA); Departamento de Geofísica de la Universidad de Concepción; Laboratorio de Geomática e Informática Aplicada del Centro EULA de la Universidad de Concepción, especialmente al técnico-dibujante Sr. Alex 


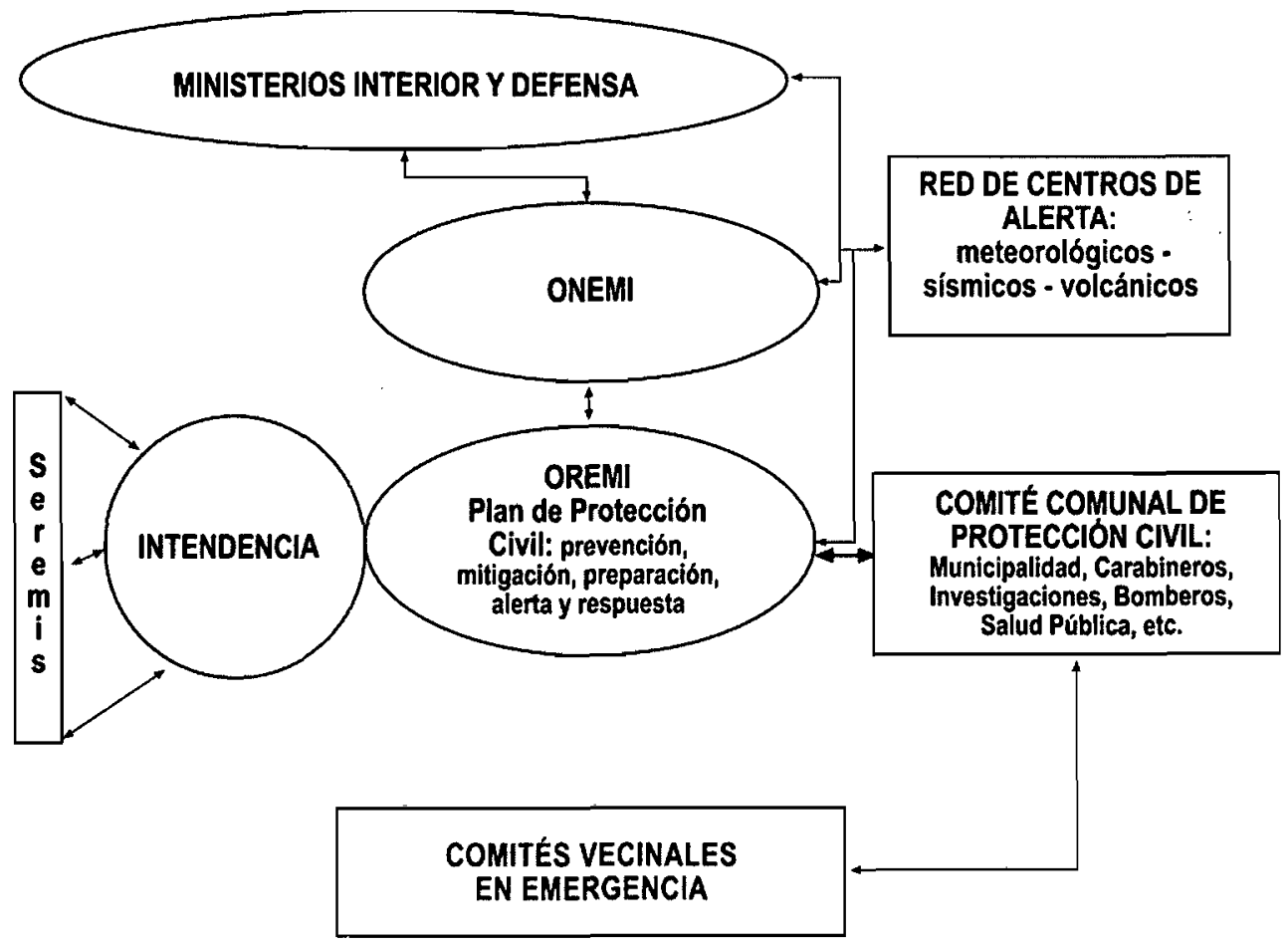

Fig. 21. Propuesta de Programa de Gestión del Desastre.

Henríquez; a la técnico-dibujante Sra. Lidia Esparza del Departamento de Ciencias de la Tierra y los vecinos Srs.: Mónica García y Mauricio Laborde de Valle Nonguén y Verónica González, Vanessa Arriagada y Christian Araneda, del sector Agüita de la Perdiz.

\section{REFERENCIAS}

ANGUITA, F. \& F. MORENO, 1993. Procesos Geológicos Externos y Geología Ambiental. Editorial Rueda. 311p.

ALARCÓN, G., 1995. Evaluación de los riesgos naturales en el área metropolitana de Concepción a través del Diario El Sur, 19601990. Memoria para optar al título de Profesor de Historia y Geografía. Facultad de Educación, Humanidades y Arte. Universidad de Concepcion: 67pp, 14 anexos.

COQUE, R., 1977. Géomorphologie. Armand Colin : 430pp
DEVYNCK, J.-L., 1973. Frentes y masas de aire de invierno en Chile Central y Sur. Cuadernos Geográficos del Sur. Vol. II. N $N^{\circ} 2$ y 3 : 5-37.

DEVYNCK, J.-L., 1970. Contribución al estudio de la circulación atmosférica de Chile. El clima de la Región del Biobío. Universidad de Concepción, Departamento de Geofísica. 158pp (Inédito).

ESSMANN ,C., 1997. Análisis, zonificación y evaluación de los desastres naturales ocurridos en el área metropolitana de Concepción entre los años 1885-1920, a través del Diario El Sur. Memoria para optar al título de Profesor de Historia y Geografía. Facultad de Educación, Humanidades y Arte. Universidad de Concepción: 102pp (Inédito).

FLORES., M. P., 1993. Zonificación y jerarquización de riesgos geomorfológicos en caleta Cocholgue, comuna de Tomé, VIII Región. Memoria para optar al título profe- 
sional de Geógrafo. Pontificia Universidad Católica de Chile, Instituto de Geografía, Santiago: 131pp (Inédito).

GALLI, C., 1967. Geología urbana y suelo de fundación de Concepción y Talcahuano. Informe final del Proyecto de Investigación $\mathrm{N}^{\circ} 75$ de la Comisión de Investigación Científica de la Universidad de Concepción: 248pp (Inédito).

INSTITUTO NACIONAL DE ESTADÍSTICA (INE), 2002. XVII Censo Nacional de Población y VI de la Vivienda.

\section{INSTITUTO GEOLÓGICO Y MINERO DE} ESPAÑA, 1987. Riesgos Geológicos. Madrid: 333 pp.

JAQUE, E., 1996. Análisis integrado de los sistemas naturales de la cuenca del río Andalién: bases para la planificación ecológica del territorio de la cuenca. Tesis para optar al grado de Doctor en Ciencias Ambientales. Centro EULA. Universidad de Concepción. : 188pp.

MARDONES, M., ILABACA, P., JAQUE, E. Y P. HORMAZABAL, 1994. Informe Final Proyecto Fondecyt No 92-0251. "Evaluación y zonificación de riesgos naturales en el área metropolitana de las ciudades de Concepción y Talcahuano" (Inédito).

MARDONES , M. \& C. VIDAL, 2001. La zonificación y evaluación de los riesgos naturales de tipo geomorfológico: un instrumento para la planificación urbana en Concepción. Vol XXVII, 81: 97-122.

MARDONES, M., 2002. Evolución morfogenética de la hoya del río Laja y su incidencia en la geomorfología de la Región del Biobío, Chile. Revista Geográfica de Chile Terra Australis, 47:97-127.

NOAA-CIRES. Climate Diagnostics Center (CDC).

UniversityofColorado.2006.www.cdc.noaa.gov/ index.html

OFDA/CRED, 2003. International Disaster Database. www.em-datnet.ucl - Brussels, Belgium.

PEÑA, F.; TAVARES, C. \& $\mathrm{M}$. MARDONES, 1993. Las condiciones climáticas como factor de riesgo natural en la comuna de Tacahuano (1965-1992). Revista Geográfica de Chile Terra Australis, 38: 83-107

PIZARRO, O. \& A. MONTECINOS, 2004. El Niño y la Oscilación del Sur. In Biología Marina y Oceanografía: conceptos y procesos. Tomo I. Camilo Werlinger I. editor : 197-224

RODINE, J.R. \& JONSON, A.M., 1976. The ability of debris heavily freighted with coarse clastic materials to flor on gentle slopes. Sedimentology. 23: 213-224.

ROMERO, H., 1985. Geografía de los Climas. Geografía de Chile. Instituto Geográfico Militar. Santiago: 243pp

SANHUEZA, R. \& C. VIDAL, 1996. Análisis integrado de los riesgos naturales en la ciudad de Concepción. Memoria para optar al título de Profesor de Historia y Geografía. Facultad de Educación, Humanidades y Arte. Universidad de Concepción: 128pp, 3 cartas (Inédito)

-STRAHLER, A., 1986. Geografía Física. Ediciones Omega. Barcelona: 767pp 